Portland State University

PDXScholar

$4-12-1985$

\title{
Documenting Archival Automation Systems: Guidelines for the Project Manager
}

Austin Moller

Portland State University

Follow this and additional works at: https://pdxscholar.library.pdx.edu/open_access_etds

Part of the Archival Science Commons, and the History Commons Let us know how access to this document benefits you.

Recommended Citation

Moller, Austin, "Documenting Archival Automation Systems: Guidelines for the Project Manager" (1985). Dissertations and Theses. Paper 3552.

https://doi.org/10.15760/etd.5435

This Thesis is brought to you for free and open access. It has been accepted for inclusion in Dissertations and Theses by an authorized administrator of PDXScholar. Please contact us if we can make this document more accessible: pdxscholar@pdx.edu. 
AN ABSTRACT OF THE THESIS OF Austin Moller for the Master of Arts in History presented April 12, 1985.

Title: Documenting Archival Automation Systems:

Guidelines for the Project Manager.

APPROVED BY MEMBERS OF THE THESIS COMMITTEE:

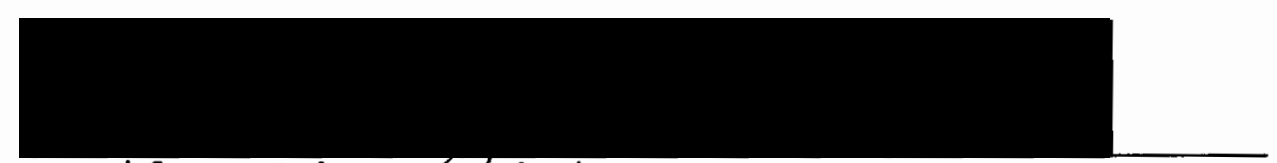

David A. Johnsop,/Chair

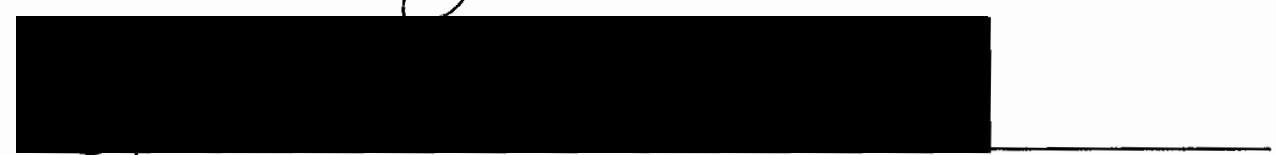

Gorgon B. Dodds

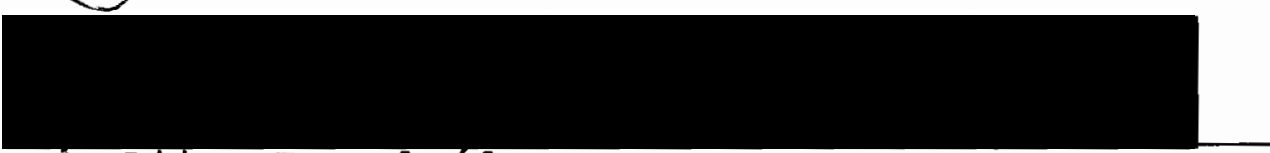

M. Liisa Fagerlund

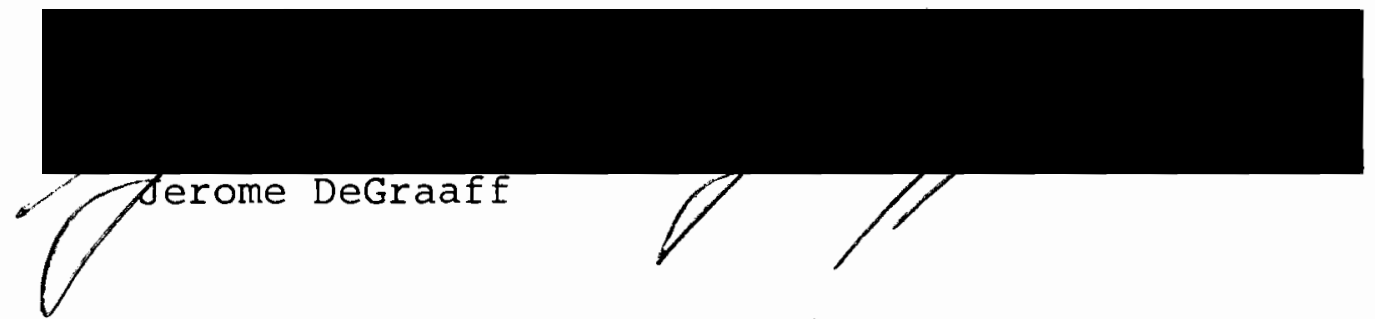

With the onset of the information age, archivists are more frequently placed in professional situations where they must work with automated systems to manage the records in their custody. They must acquire new skills to use this technology, including system analysis, system planning, and 
the principles of computer operation. An area that is frequently neglected, however, is that of developing and maintaining in-house project documentation for systems once equipment is in place and implementation has begun. This oversight leads to poor training strategies, inconsistencies in input and output, and information loss when personnel changes occur.

Project documentation is the group of records that describe the system the archivist creates. It is a communications tool, developed by the project manager as a reference document for administrative and operations purposes, and to train users.

The documentation guidelines assembled in this text were developed by the author while implementing automated systems over a six-year period. They are arranged in five groups. SCOPE discusses ways to introduce the user to the project, the equipment, and to the concept of the project manual. SYSTEM ORIENTATION contains strategies for more detailed instruction on the equipment. INPUT shows how to describe the data base design and instruct the user on entering data. OUTPUT provides a format for profiling and generating reports. And OPERATIONS AND MAINTENANCE outlines the tools the project manager needs to maintain the system. Each documentation technique is illustrated with an example that represents its general characteristics. Some 
are more suited to large mainframe systems and others are more useful in microcomputer applications, but every effort was made to present them in as generic a fashion as possible so that archivists can choose and adapt the tools best suited to their needs.

Development and use of in-house documentation is a records management function, necessary to maintain an ongoing record of system activities, data contents, and changes. This text is intended to give archivists guidance on the types of record-keeping required to ensure the integrity of the systems they create. 
DOCUMENTING ARCHIVAL AUTOMATION SYSTEMS:

GUIDELINES FOR THE PROJECT MANAGER

by

Austin Moller

(C)

A thesis submitted in partial fulfillment of the requirements for the degree of

\author{
MASTER OF ARTS \\ in \\ HISTORY
}

Portland State University

1985 
TO THE OFFICE OF GRADUATE STUDIES AND RESEARCH:

The members of the Committee approve the thesis of Austin Moller presented April 12, 1985.

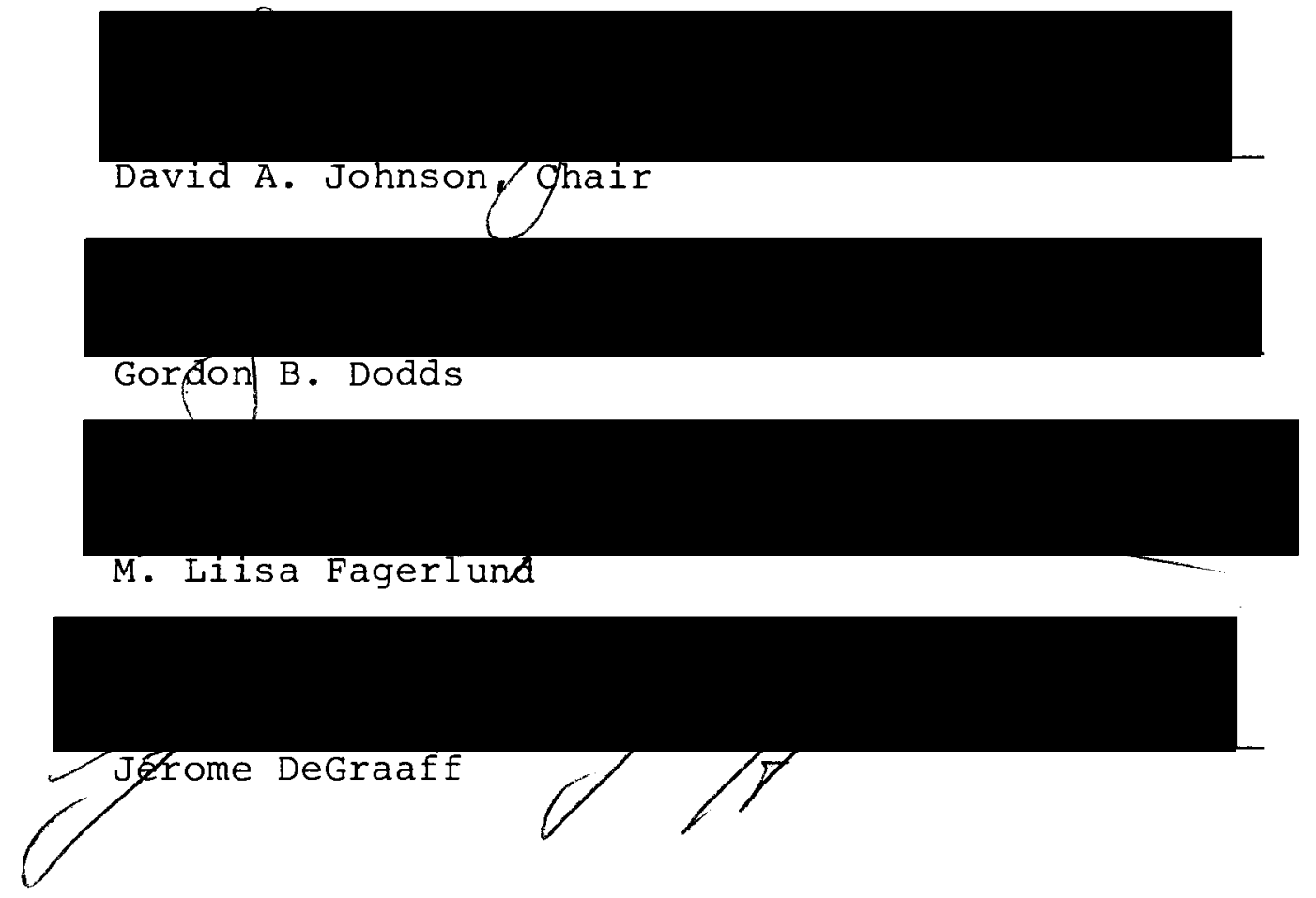

APPROVED :
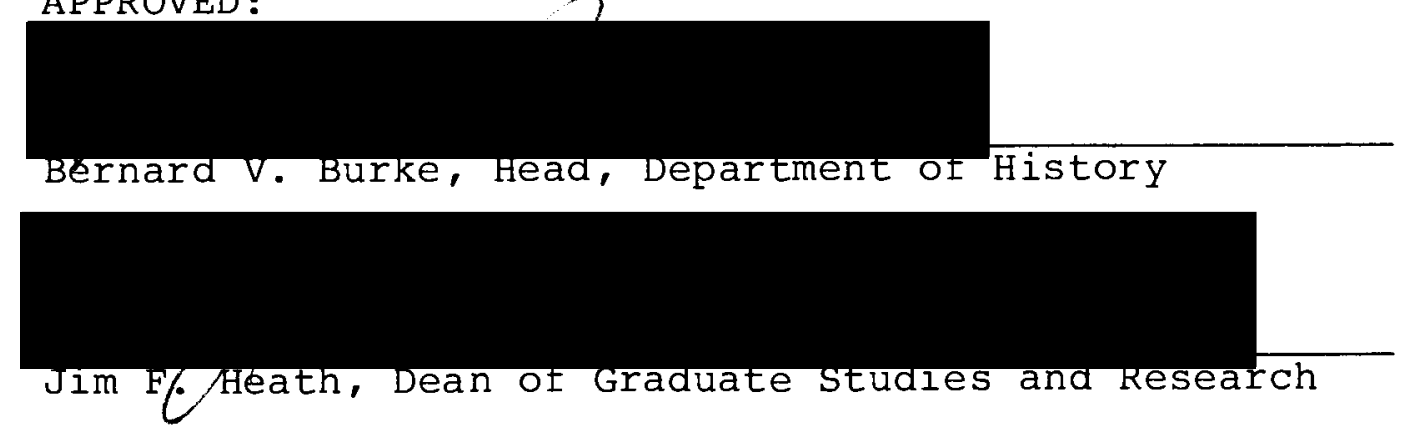
ACKNOWLEDGEMENTS

My thanks to the following persons, each of whom contributed to this effort in a special way:

M. Liisa Fagerlund

Utah State Archives

David A. Johnson

Portland state University

Gordon B. Dodds

Portland State University

Jerome deGraaff

Portland State University

Stanley T. Parr

Portland Archives and Records Center

Richard V. Szary

Smithsonian Institution

and

Nancy Morse Torp

Portland, Oregon 
TABLE OF CONTENTS

PAGE

ACKNOWLEDGEMENTS. . . . . . . . . . . . . . . . . iii

LIST OF FIGURES......................

CHAPTER

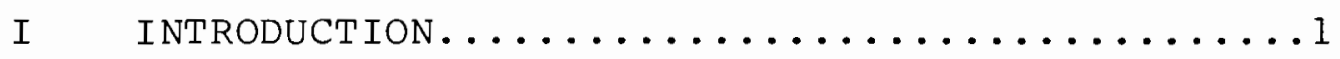

I I DOCUMENTATION'S FORMS AND PURPOSES $\ldots \ldots \ldots \ldots 6$

What is Documentation?

Studies Highlight the Importance of Documentation Documenting in the Archival Environment Project Documentation as a Learning Tool

Structure and Characteristics of a Project Manual

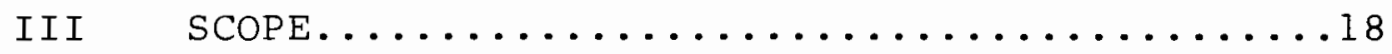

Project Introduction

Equipment Introduction

Manual Introduction

IV SYSTEM ORIENTATION..................

Glossary

Operations and the Operating system

Application Software 


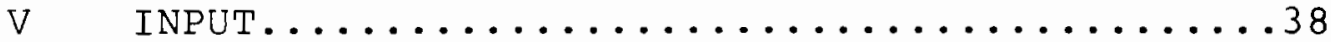

Definitions and File Information

Data Base Design

Data Entry Instructions

File Updating

Data Entry Controls

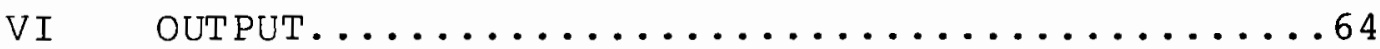

Report Inventory

Report Profiles

Reporting Controls

VII OPERATIONS AND MAINTENANCE............76

Risk Management

Supply Inventory

Security

File Integrity

Work Plan

VIII

CONCLUSION. .86

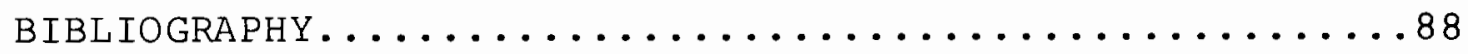


LIST OF FIGURES

FIGURE

PAGE

1. Sample Project Introduction, compiled from

Portland Historic Resource Inventory

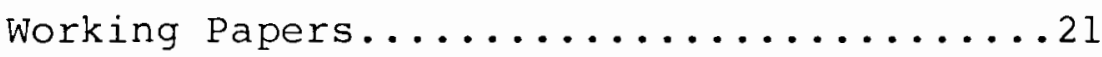

2. Equipment Introduction, Junior League of

Portland Computer Operations Manual.....24

3. PARC System Architecture Diagram............27

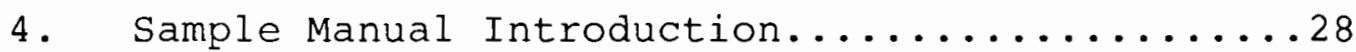

5. Computer Concepts Quiz, extracted from the

Junior League of Portland Computer

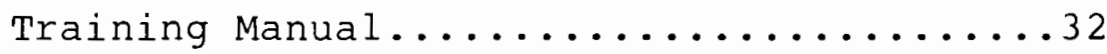

6. Operating System Guidelines for IBM-XT, Junior

League of Portland Computer Training

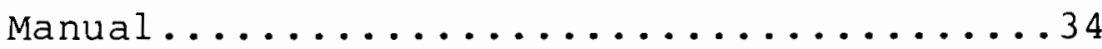

7. File Information, Data Entry Instructions and

Style Manual, Junior League of Portland

Membership Information system.........41

8. File Information, Historic Resource Inventory

SPINDEX Operations Manual...........42 
9. Data Summary, Historic Resource Inventory SPINDEX Data Entry Instructions and

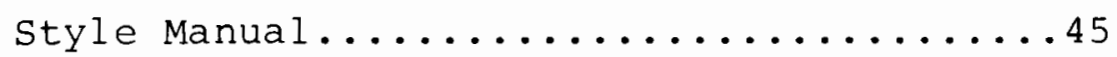

10. Extract, Proposed Format for SIBIS

Circulation Module, Smithsonian Institution..................46

11. Record Format, Historic Resource Inventory

SPINDEX Data Entry Instructions and

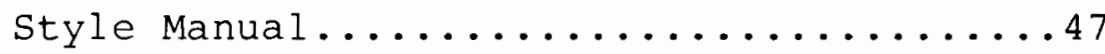

12. Extract, Data Entry Instructions, Historic

Resource Inventory SPINDEX Data Entry

Instructions and style Manual..........50

13. Extract, Change Control, Bureau of Traffic

Engineering Library Reference Guide and

Updating Procedures Manual...........58

14. Data Entry Control Form, Data Entry

Instructions and style Manual, Junior

League of Portland Membership

Information system................62

15. Sample Report Inventory, compiled from

Historic Resource Inventory SPINDEX

Operations Manual.................65 
16. Sample Report Profile, compiled from Historic Resource Inventory SPINDEX Operations

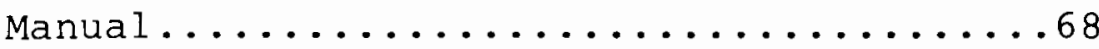

17. Sample Report Profile, compiled from Junior League of Portland Computer Operations Manual......................

18. Job Control Register, Historic Resource Inventory SPINDEX Operations Manual.....74

19. Project Control Chart, Historic Resource

Inventory SPINDEX Operations Manual.....75

20. Sample Supply Inventory, compiled from Junior League of Portland Computer Operations Manual..............78

21. Archive Tape Assignment Log, Historic Resource Inventory SPINDEX Operations Manual.....81

22. Extract, Work Plan 1983-84, Historic Resource Inventory SPINDEX Operations Manual.....83

23. Expense Log for Task \#6, Historic Resource Inventory SPINDEX Operations Manual.....84 
CHAPTER I

\section{INTRODUCTION}

This writer first began working in the City of Portland Archives in July of 1979. The program had just won a threeyear development grant from the National Historical

Publications and Records Commission (NHPRC) to bring the city's archival records under control, and had purchased the SPINDEX data base management system to provide automated access to these records.

Next to the traditional IBM typewriter was a not so traditional CPT 4200 word processor, which consisted of a typewriter, a monitor, and a dual cassette tape drive in which data was recorded and corrected through painstaking tape-to-tape revisions. Completed cassettes were sent across the country to Washington DC to be converted to computer tape at the National Archives. Tapes were then sent back to Portland where they were loaded onto our county computer. If there was an error, we had to wait until the next tape was sent to make the correction. Report formats were limited to the horizontal, and were printed in allcapital letters on oversize green-bar paper. 
Just six years later, the Portland program enters data on a WANG word processor, whose glossary and editing capabilities are far advanced. Data is transmitted directly to the county's computer via telephone line, and a variety of laser printing options is available. Publications are designed on the computer and transmitted back to the WANG where they are edited and printed. This technology is now so taken for granted that to function without it seems inconceivable.

Generally, archival uses for the computer fall into two categories. First, it is an administrative tool on which the archivist builds an information management system to control internal operations. A collection can be tracked from the moment it comes through the door, through accessioning, inventory, processing, description, final disposition, and shelf location. In addition, computerizing user statistics is an excellent way to pinpoint high-use records, which aid storage planning and collection development. Secondly, the computer assists in the production of finding aids to collections, chiefly in the form of registers and indexes.

Five years ago few archives could afford to automate access to their holdings. Today the micro computer revolution has made this technology available to just about everyone. Unfortunately, there is a documentation gap. 
Computers come equipped with hardware and software documentation that shows the user how the machine and the programs work. There is a tendency to then proceed with implementation using these tools but without developing any records more specific to the application.

It is the archivist's responsibility as a manager to develop documentation for each application that is being implemented. Computers demand the discipline of arranging data logically and consistently. Having a computer is like having an extra brain, except that it cannot reason or make judgements, nor can it function effectively on the casual judgements of people. Its activities, or "duties" in human terms, must be clearly defined in order for the machine's work to be carried out smoothly and to manage change in an orderly fashion.

After working on a variety of projects, large and small, mainframe and micro, the author has discovered some basic documentation techniques that apply no matter what kind of system is in use. These basics are presented here as guidelines for documenting an automation project.

The examples cited in this text are taken from project documentation developed over a five-year period for the Portland Archives and Records Center (PARC) and over a three-year period for the Junior League of Portland. In addition, the author spent three months observing the 
automation process underway at the Smithsonian Archives in Washington DC.

At the Portland Archives, SPINDEX application software was used in the development of a number of archives and records management data bases, including the city of Portland Archives Guide, the Portland Historic Resource Inventory, and the Portland Water Bureau's Administrative Filing system. In contrast to the more complex mainframe architecture required for PARC operations, the Junior League bought an IBM-XT to serve its information needs, which vary from maintaining personnel files on its members to expanding its involvement in community projects and training. The Smithsonian Institution Bibliographic Information system (SIBIS) offers a third perspective in that it is a library system within which archivists at the Institution are describing their holdings, a process which has raised many questions and problems regarding training and the interpretation of terms and requirements.

As varied as these three situations may seem, they share common documentation needs. Computers may differ in size and character, but once they are installed and a project begun persons must be trained to use them, input and output must be defined, and data bases must be maintained. Experience has served to emphasize to the author the importance of documentation as a management tool, and as a 
means of achieving the proverbial textbook management objective: the organization and utilization of human and material resources to reach a stated goal. 
CHAPTER II

DOCUMENTATION'S FORMS AND PURPOSES

A computer can save the archivist a great deal of work in that it can quickly perform many traditionally time consuming jobs such as cataloging and indexing. However, having a computer also requires the introduction of new and different kinds of work, concepts, and discipline. Unlike people, a computer will always be consistent, but it must always be told what to do. When managing an automation project, it is necessary to build a structure of people and documentation to support operations and make the best use of the machine's capabilities.

What is Documentation?

Documentation is any collection of information that supports a process or procedure, manual or automated. It describes a system or function, specifies how it is carried out step by step, and gives it an identity in the overall scheme of things.

Though the term "documentation" is not new, it has come into increased use in the past several years as a description of the printed material that is packaged with a 
computer or a piece of software with the purpose of communicating to the user how the machine or the program works. As computers have become more widely distributed, the nature of documentation has changed as well.

In the "old days" computer transactions took place chiefly on the corporate level. Such a purchase represented a significant investment for a company, which hired programmers and engineers who were dedicated to operating and maintaining the system. The sale was also significant enough to the vendor to cause it to assign a customer support person, often full time, to service the contract. Documentation was highly technical, designed for professional data processing users.

As computers got smaller and cheaper, the human resources allocated to maintain them shrunk accordingly, with the result that product documentation has become less oriented to the system technician and more oriented to the untrained user. This person has little interest in how the computer interprets hex codes or processes information -- he or she is concerned only with making the machine perform a desired task. However, increased accessibility and lower prices have their costs. The vendor feels little obligation to provide more than minimal customer training and support, with the result that the user must be self-taught and 
develop an organized approach to the management of the systems he or she creates.

Documentation does not stop when the computer is delivered with its boxful of instruction manuals. The archivist will use the machine to build one or more informational data bases to support operations from then on. Just as hardware and software documentation describe the "raw materials," so project documentation will define the product the archivist builds from them, and serve as a format for explaining that product to others.

Studies Highlight the Importance of Documentation

Most of the literature on documentation today is written to support the development, management, and maintenance of software, the programs that make the computer work. Several publications have been issued by the United States National Bureau of Standards (NBS) and the National Technical Information Service (NTIS) recommending guidelines for these activities. Software development takes the computer programmer through many of the same phases an archivist must go through when planning for automation: system analysis, definition of functional requirements, system design, and testing. Government studies have determined, however, that a frequently neglected area is software maintenance, "the performance of those activities required to keep a software system operational and 
responsive after it is accepted and placed into operation" (Martin 6).

Roger Martin and Wilma Osborne, authors of a 1983 NBS special publication entitled Guidance on Software Maintenance, conducted interviews with administrators of federal data processing systems and polled them on what they felt to be their most common problems. Some of these were technical and included coding and language inconsistencies as well as changing hardware environments. Others were managerial, such as lack of proper user and operator training and the failure to enforce standards. The authors concluded, however, that even the technical problems were in many cases the result of poor management. There was a tendency to want to get a project going without paying enough attention to maintenance details, and once the programs were in operation there was a failure to document the little adjustments and enhancements that were made to perfect the system. Maintenance is less exciting and innovative than creation (Martin 4).

Documenting in the Archival Environment

Although the archivist managing an automation project need not be concerned in most cases with the details of programming software, the goal is the same - creation of a structure for system maintenance. Documentation is a 
discipline. Human beings are capable of carrying out a task a number of different ways, depending on the circumstances. They are reactors and decisionmakers who evaluate a situation and take appropriate steps. A computer can't do anything by itself -- it must be directed by people. And because it is built on logic, it mist be told exactly what to do. The more complex the task, the more critical it is that the machine be instructed properly and consistently. And the more persons involved in a project the more important it is to build and maintain a procedures and operations manual to ensure this.

Thus, in addition to maintaining system quality, documentation is also a communications tool. This is an important concept in implementing an automated system, because so much depends on the computer receiving the right data, the right instructions, and producing the desired product. This in turn depends on the project participants and the training and guidance they receive.

One of the archivist's early actions should be to designate a center of communications, a "Person In Charge" (PIC) who has responsibility for organizing the project and coordinating activities, and who serves as the principal decisionmaker and documentor. In the data processing field, this person is generally known as the data base administrator, or DBA. Since in an archival environment it 
is rare for a staff person's time to be dedicated solely to system development, PIC will be used in this text.

Archival project documentation serves the PIC in a number of ways. First, it is an administrative tool. A project is planned and budgeted, and controls are developed to make sure it stays on schedule. Furthermore, automated systems demand consistency - they are useless if data is not entered according to design. At the same time, that design is quite flexible, and circumstances may require the introduction of new data. There must be a record of what "is" in order to add what "will be" and react to developments in an orderly manner. Changes also occur in the system overall. It is not uncommon to introduce new and improved hardware and software at various intervals in the Iife of a data base. Good documentation makes the conversion process go more smoothly.

Documentation is also a reference tool. Developing a procedures and operations manual has the advantage of collecting all the information about a project in one place. Getting staff persons to use it is an essential part of their orientation. "Procedures" are often frowned upon as too stringent and authoritative. It must be stressed that use of a computer requires this additional discipline. Staff must develop the habit of using the manual and contributing to it. 
In addition to administration and reference, documentation is an invaluable training aid. This is particularly true when changeovers occur. A project manual remains as a record of how things are done, avoids disruption when an employee leaves, and makes it easier for a new person to step into the process. It may also have a tutorial function, depending on the computer literacy level of the project participants and the quality of the documentation supplied by the vendor. Especially with new users, it is often helpful to condense the latter at the beginning, giving learners the basic background and instructions they need to start on a job and have some success. This has the advantage of building their confidence and giving them experience which will make the printed manuals more meaningful in the long run.

Project Documentation as a Learning Tool

There is a growing fund of knowledge in an area which can be described as "Software Psychology," which studies human-computer interaction with the goal of improving the relationship between the two, chiefly in the area of software engineering (Shneiderman 3). The consideration of human factors in hardware and software design is on the upswing as more persons use computers and the market becomes more competitive. Sales are depending increasingly on the user's ability to understand and learn to use the product. 
Donald A. Norman, a psychologist at the University of California at San Diego, has studied this learning process, and presents it in the context of developing "mental models." He begins an article on same with the following statement:

"People's views of the world, of themselves, of their capabilities, and of the tasks they perform . . depend heavily on the conceptualizations they bring to the task" (Norman 1).

He defines the task to be learned as the "target system" and the user's "mental model" of that system as his or her image of the task, which is shaped by positive or negative interaction with it. The designer of the target system has another conceptual view of it, which is based on the functions it was designed to perform. It is up to the designer to create a "conceptual model" of the target system that guides the user to understand it and use it in the way in which it was intended.

Norman concludes his article with three criteria for an effective conceptual model: learnability, functionality, and usability. These are valuable guidelines for the PIC preparing to document an automation project. The material should be organized and easy to understand, its orientation to specific functions and products should be clear-cut, and it should be easy to use. In Guidance on software Maintenance, Martin and Osborn conclude that "one of the 
major problems in software maintenance can be summarized in a single phrase - a failure to communicate." They cite failure to overcome language or jargon gaps, failure to communicate requirements from one technical level to another, and failure to communicate in time and over distance (Martin 15). Product documentation for a single system can be prepared by technical writers at any number of different times and locations, and these persons are rarely available as resources. To successfully implement an automation project, the PIC must fill this gap and develop a communicating structure that serves participants information needs.

\section{Structure and Characteristics of a Project Manual}

The discussion that follows is based on the assumption that a project has been planned. Briefly, this involves a system analysis that studies existing methods, identifies the functions that are carried out, and defines the information items, or data elements, that are processed. The next step is to translate this analysis into functional requirements, in other words a clear statement of what the archivist needs an automated system to do. Once this is understood, appropriate equipment can be purchased. From this point specific application begins: the data base is designed, data structure defined, a work plan is developed, 
information is keyed in, reports are generated, and the system is maintained.

The PIC develops a procedures and operations manual to administer a project and provide the users with the information they need to carry out its functions. It is instructional, procedural, and task oriented. It serves as a central point of reference and record of activities and decisions.

How project documentation is organized depends on many variables, including the kinds of hardware and software in use, the quality of the documentation that comes with it, and the computer literacy level of the participants. As an overall rule, a project manual should start with the general and get more specific. It deals first with the system as a whole, then its component parts, then its various functions, and finally its data characteristics. It first describes a system or function and then provides the procedures and instructions the user needs to carry it out.

Project documentation also includes tools to monitor progress and evaluate data products at various stages. These need not be intimidating to participants - some means has to be developed to make sure the project is advancing according to schedule and, indeed, if there is a lot of repetitive work to be done like data entry, having a progress chart can be a big morale booster. Similarly, 
particularly in the initial phases, regular evaluation of the product can be an excellent training tool and will catch many performance or procedural problems in their early stages.

The remainder of this text discusses guidelines for a project manual, with examples extracted from the sources mentioned in chapter I. It is arranged in five chapters, each one corresponding to a recommended section of the manual. The first, SCOPE, is entirely descriptive and is intended to introduce the user to the project as a whole. The second part, SYSTEM ORIENTATION, provides more detailed information about the computer and the software, particularly the operating system.

Section three, INPUT, is a guide to the data entry process. It includes the data base design and data element definitions, data entry instructions, and style and editing guidelines. Section four, OUTPUT, introduces the user to the programs that manipulate the data, profiles reports, and gives instructions on how to produce them.

The fifth part, OPERATIONS AND MAINTENANCE, is used chiefly by the PIC. Maintenance pertains both to the care and upkeep of the hardware and to the security and integrity of the data base. The PIC may also use this section for administrative purposes like recording progress and budget tracking. 
It is unlikely that the PIC for any archival project will feel the need to use all the tools provided in the coming chapters. Some are more suited to large systems, others more pertinent to smaller ones. It is the intent of this discussion to emphasize the need for project documentation, whatever its form, and to stimulate the archivist's thought processes towards determining what he or she requires to manage an automated system and communicate with its users. 
CHAPTER III

SCOPE

The SCOPE and SYSTEM ORIENTATION sections are of particular significance to the uninitiated user. They are his or her introduction to the project and to the idea of automation, and as such are the PIC's best opportunity to make a clear first impression.

Ideally they are presented to participants in one or two orientation sessions where they can be reinforced with visuals and demonstrations. The chief purpose is to get persons to focus on the material -- if it is handed to them at their desks, they may not have time to read it or, if they do, they may not comprehend it fully. To return to Norman's discussion of mental models in Chapter II, the orientation allows the PIC to present his or her conceptual model of the target system and positively influence the user's initial impression of it. Questions can be answered on the spot. People can make suggestions. Moreover, the PIC has the opportunity to establish an image as the center of communications and decisions for the project.

The SCOPE section is descriptive, not technical. Its purpose is to give participants an overview, explaining 
goals and objectives, functions, and where the computer fits in. It is divided into three sub-sections: the project Introduction, Equipment Introduction, and the Manual Introduction.

\section{Project Introduction}

This defines what, Where, when, How, who, and why of the project. It can be as brief as a single paragraph or several pages in length, and cover any or all of the following areas.

History. If there is background information that will improve participants' understanding of the work to be done or help clarify certain goals, it is presented here. It may be that the automation task at hand is part of a larger effort, in which case it should be put in perspective. If the project has been undertaken to address a special problem or need, the PIC can use this section to describe how it was identified, giving a brief summary of the system analysis process if necessary, and concluding with a discussion of expected benefits and improvements.

Goals and objectives. This is a synopsis of the work plan, which is discussed in more detail in the OPERATIONS AND MAINTENANCE chapter. It sets forth the expected final products or results of the project, and summarizes the tasks that must be completed to achieve them. 
Organization and Process. This section describes the overall organization of the project, departmentally and functionally. The PIC may choose to draw a simple flow chart or prepare a script that illustrates how information is processed and who is performing which tasks.

Policy Guidelines. This part consists of any

directives required to establish lines of authority and priorities for use of the automated system. If equipment is to be shared among several departments or projects then it is helpful to have a plan for use, down to specifically assigned times if necessary, and agreements about the purchase and control of supplies. Statements reflecting wider organizational concerns are included as well, such as restricting personal use of the equipment, and security.

Setting policy is an important part of implementation because it establishes many of the restrictions and conditions under which the PIC must work, and to some degree dictates the shape and content of the rest of the manual. If security is a matter of policy, then the PIC must consider including appropriate procedures in the OPERATIONS AND MAINTENANCE section. If the system is to be shared, then the amount of time allocated per user will affect the way the PIC develops the work plan.

A sample project introduction follows in Figure 1. 
Sample Project Introduction Portland Historic Resource Inventory

History and Goals. Proposed to the Portland City Council in late 1979 , the Historic Resource Inventory (HRI) has as its overall goal the identification of Portland's significant architectural, historical, and cultural resources.

When the HRI got underway in July 1980, the Portland Archives and Records Center (PARC) proposed automating the data collected, for the following reasons. First, the project involved the creation of a significant volume of records that could be reduced by magnetic storage. Second, automation would streamline the information retrieval process for the inventory staff and eliminate the time-consuming job of producing index card files and tabulating reports manually. Finally, the city's Archivist saw this as a opportunity to develop a reference base in local history and architecture which would consolidate information previously spread out among several city and county agencies.

Organization and Process. The HRI is supervised by the Inventory Coordinator in the Portland Planning Bureau. Properties will be identified by an architectural historian conducting a windshield survey of the city, and by a historical consultant who will connect buildings and sites to important persons and events in the city's history. A team of researchers will then complete a six-page inventory form for each address. These will be forwarded to PARC for data entry.

To ensure the accuracy and integrity of the data collected, it must be reviewed by Citizen and Technical Advisory Committees. In addition to data entry, therefore, PARC will also produce property profiles and special indexes to aid these processes. After they are complete, we will make all necessary corrections and additions to the data base, and produce the copy for the final published reports.

Policy Guidelines. This manual is to be used by PAR staff in carrying out their required tasks. It is also a reference document for project researchers so they may have a better understanding of the data requirements of the automation process.

Final contents of the data file created are the responsibility of the Inventory Coordinator. No 
major corrections or additions should be made without consulting this individual. If questions arise in the data entry or editing process, they should be directed first to the Archivist, who is the PARC project manager, who will consult the Coordinator if necessary.

Data will be entered at PARC on a WANG word processor. A second terminal has been procured for the HRI, and until the initial project requirements are completed, it has priority use of this terminal.

Inventory Coordinator (name/phone) Archivist (name/phone)

Figure 1. Sample Project Introduction, compiled from Portland Historic Resource Inventory Working Papers.

The above example summarizes the general goal of the HRI project and PARC's more specific objectives in seeking to automate the data. It provides an organizational overview, stating who is in charge of the project and who is involved in its various activities, preliminary to a more detailed action plan.

The first policy guideline is worth noting: it states the manual's intent as a training and reference tool for both PARC staff and the project researchers. One of the problems encountered early on was that communication between these two groups was inadequate. The persons collecting the data were not keying it in, and they did not understand the constraints automation imposes on language and terminology, nor did they recognize the importance of using authority lists and thesauri. As a consequence, data entry personnel 
were using valuable input time to edit verbose sentences and look up words in the style manual. Orienting the researchers to their needs in a brief session solved the problem. This serves to stress again the importance of communications, not only writing things down but also verbalizing and demonstrating them in training groups.

\section{Equipment Introduction}

Keeping in mind that the manual is designed to orient the user in stages -- starting with the simple and moving towards the technical -- this first introduction to the equipment should be as descriptive as possible. This is not always easy to do, especially when dealing with a more complex mainframe system, but participants often don't need a lot of technical information to get the job done. This section is a preliminary to SYSTEM ORIENTATION. It describes the hardware and software resources and discusses very simply how those resources process information. One approach to this task is to describe system components in inventory form. The following example was developed for an IBM-XT. 
IBM-XT System Architecture

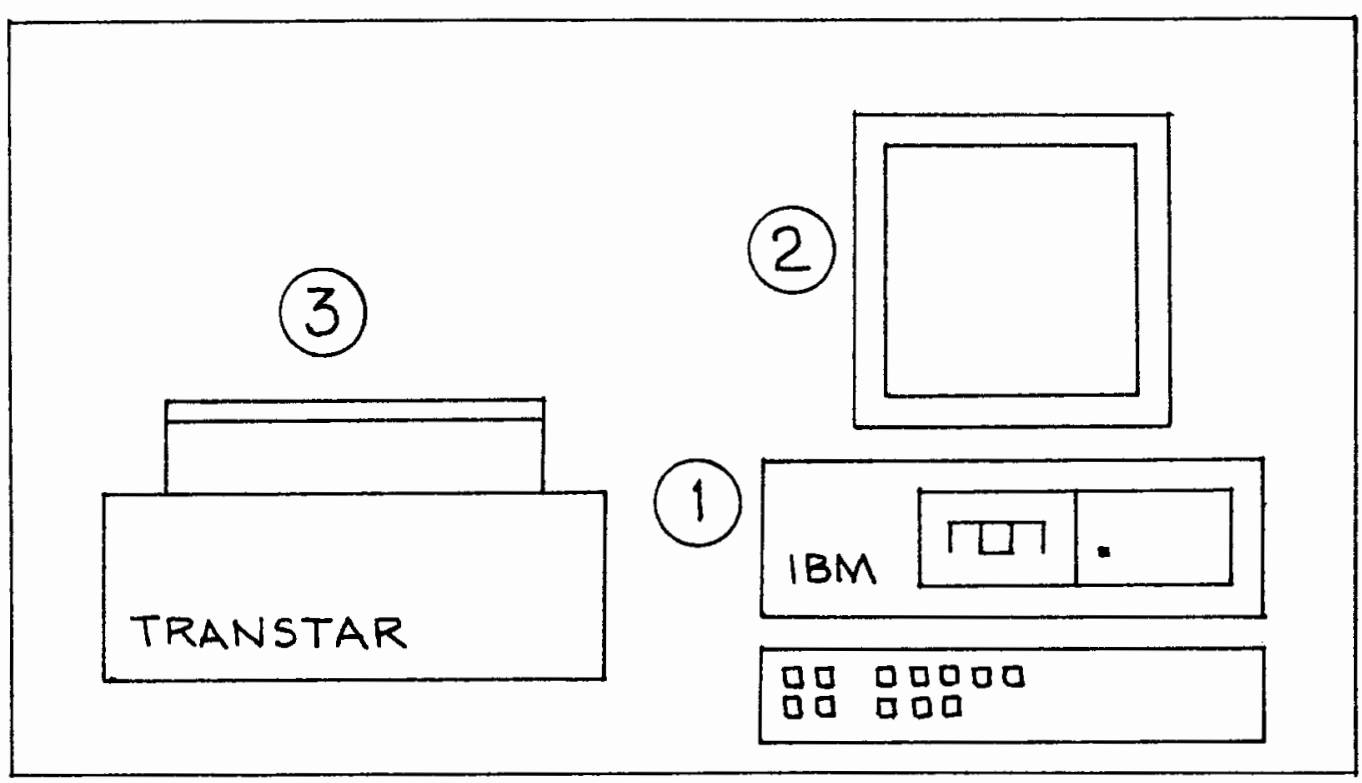

Item \#l: Central Processing Unit (CPU) with $128 \mathrm{~K}$ RAM

Description/Features: This is the "brain" of the computer. RAM is the work area that is used when it is carrying out instructions or recording the data we type in. $128 \mathrm{~K}$ is the equivalent of 128,000 characters, or "bytes" of information. The RAM is a temporary storage and processing area. It is erased every time the computer is turned off and every time you switch from one software package to another. There are two ways to store data permanently:

Fixed Disk: also called the hard disk, or C Drive,

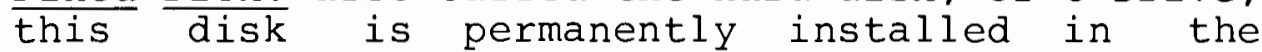
computer. It is capable of storing 10 mega- (for million) bytes of information. This area will store membership data files and financial records.

Floppy Disk: $51 / 4 "$ magnetic disks placed in the disk drive, also called the $A$ Drive. Each of these will hold 360,000 bytes of information. Committee files will be stored on floppies.

Documentation: General information about the IBM-XT is found in the GUIDE TO OPERATIONS and in the SYSTEM ORIENTATION section of this manual. 
Tutorials: There is a tutorial disk entitled "Exploring the IBM-PC." Select the one for monochrome display, and follow the instructions on the accompanying instruction card.

\section{Item \#2: IBM Monitor}

Description/Features: Just like a TV screen with an attached keyboard, the monitor is used to display all of the information you are keying into the computer.

Documentation: same as above

Item \#3: Transtar Letter Quality Printer

Description/Features: This is a high quality printer with a tractor that will feed continuous-form paper. The tractor can be removed so that individual sheets can be used, just like a typewriter.

Documentation: An operations and maintenance manual provides instructions for assembly, tractor installation and removal, ribbon changing, and interpreting error messages.

\section{SOFTWARE}

\section{Item: IBM Disk Operating system (DOS)}

Description/Features: This is the set of programs that make the computer work. Without the Dos, none of the hardware components would be able to communicate with each other, nor would you be able to activate any other application software, like word processing or filing. It is stored permanently on the hard disk and loads automatically when the computer is turned on. The Dos disk also includes programs called Utilities, which enable you to manipulate files from the operating system. These include Disk Directory, Disk Copying, Erasing Files, and Editing.

Documentation: DOS Manual, and basic commands provided in the SYSTEM ORIENTATION section of this manual. 
Item: PFS Application Software

Description/Features: Application software is a term that is used when referring to programs that perform specific functions for the user. The JLP has purchased three PFS packages, PFS WRITE for word processing, PFS FILE for electronic filing, and PFS REPORT for producing reports from PFS files. They are easy to learn and will interface with one another, which means that while data is keyed into the computer using one set of software instructions, in certain cases it can be manipulated by giving instructions from another package.

Documentation: There is one manual for each of the PFS packages. PFS WRITE and PFS FILE can be studied independently, though certain chapters will explain how one relates to the other in performing certain functions. PFS REPORT should be studied in conjunction with PFS FILE.

Tutorials: Each software manual provides easy explanations and samples for the user to practice with. In addition, PFS WRITE comes with a sampler disk containing several practice documents.

Figure 2. Equipment Introduction, Junior League of Portland Computer Operations Manual.

The inventory approach works well with smaller computers where participants must become familiar with and proficient at operating the entire system. They must understand what the components are and know what documentation and training resources are at their disposal. With larger systems, this approach can be supplemented with a diagram that illustrates how information is processed throughout. At the Portland Archives and Records Center, for example, data is keyed into word processors and then transmitted to the county's mainframe computer, located at 
its Data Processing Authority (DPA). The PIC then goes to the city's Bureau of Computer Services to submit the programs that update the master file and generate the reports. Reports can be printed automatically on a laser printer or they can be routed back to PARC's word processor for further editing. While PARC employees aren't involved with operating the large computer at all, a diagram of the system will help them see the role it plays.

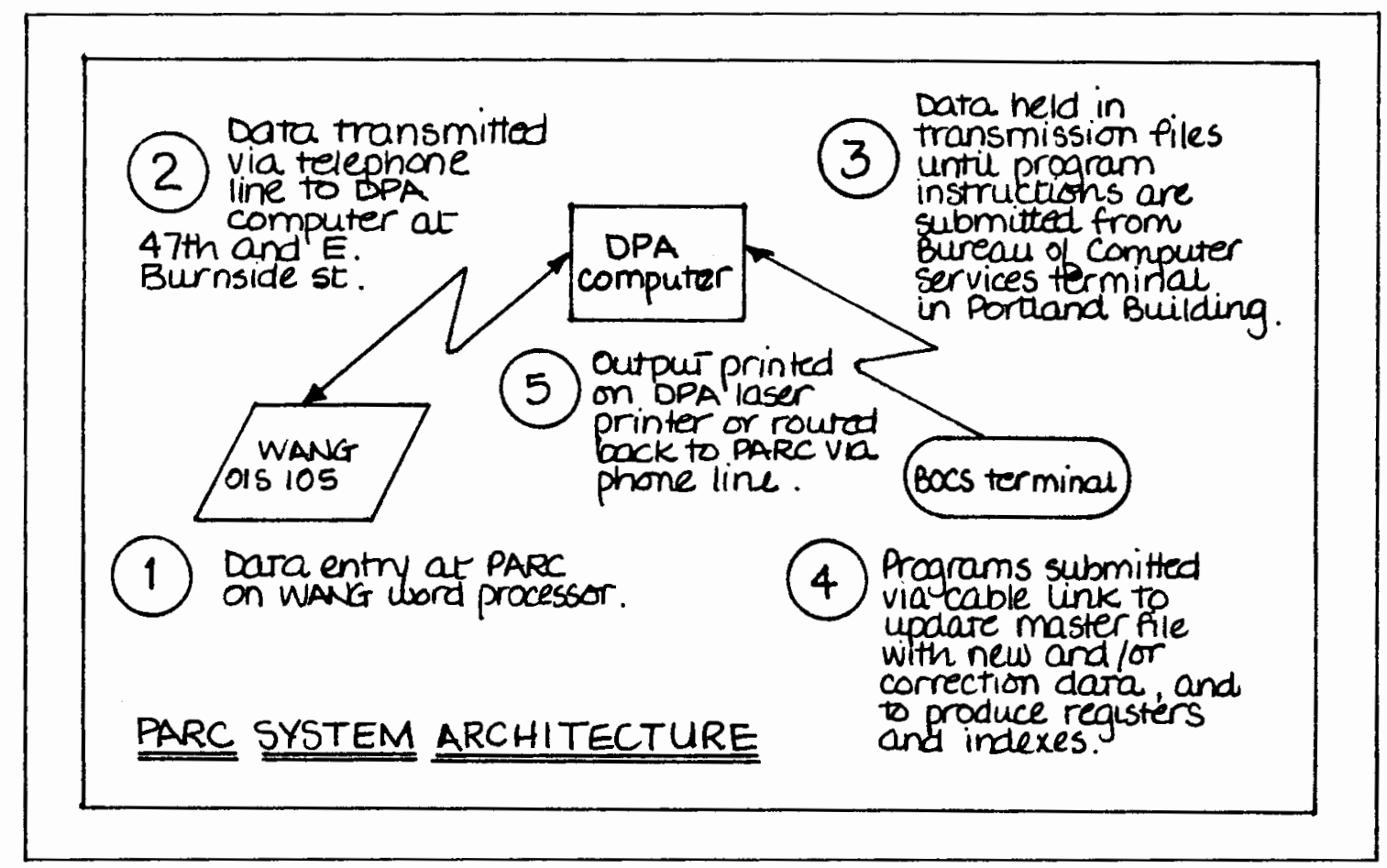

Figure 3. PARC System Architecture Diagram

Manual Introduction

This section is essentially an annotated table of contents and can be so titled if the PIC prefers. It 
identifies the manual's sections and sub-sections, tells the user where to find them (section number, page number, etc.) and, if the title is not descriptive enough, gives a brief explanation of what they are for.

For example, the introduction to an INPUT section might look like this:

INPUT/DATA ENTRY

a. Definitions and File Information........... Basic terms, file names, and other information you need to get started.

b. Data Base Design....................

Information that will be keyed into the computer.

d. Data Entry Instructions................ Field-by-field instructions for keying information into the data base.

Appendices..........................

Special supplements to the data entry instructions provide additional information where required. These include style guidelines and authority lists. The user is referred to the appendices at specific times in the instructions.

e. File Updating...................... Procedures for correcting data, adding new data, or deleting data.

f. Data Entry Control Charts................ Progress charts to be completed by data entry personnel as work progresses.

Figure 4. Sample Manual Introduction 
The contents of the manual are determined by the size and complexity of the project as a whole and by the documentation structure the PIC chooses to use. Notebooks are a convenient way to arrange material because they are easily updatable and store neatly. If the volume of documentation is too great for one notebook, the PIC can break it down, giving each participant his or her own, and limiting the contents to those parts needed to perform the tasks assigned. Not everyone needs the OPERATIONS AND MAINTENANCE section, for example, because most of those functions are performed by the PIC alone.

An alternative is to give each participant an introductory manual and then create individual notebooks for each function. For example, there would be a single INPUT manual that would be used whenever anyone did any data entry. This approach is preferable when a project is tightly controlled and the PIC needs a centralized format for monitoring progress.

Whatever the structure, the Introduction to the Manual is used to describe it. Participants need to know what to use when and, if materials are to be shared, where they will be stored. Again, it must be stressed that documentation is a format for communications, and a resource, and it is critical that everyone understand its organization and know where to go for information. 
CHAPTER IV

SYSTEM ORIENTATION

SYSTEM ORIENTATION is a training section which introduces participants to the technical operations of the computer and the software. The PIC's most important role in this area is that of information coordinator and interpreter. He or she must arrange all the available training resources - vendor, consultants, staff persons, documentation, and others - with the goal of assembling clear instructions on how to make the system work. It is the foundation for the data entry process, for the more comfortable persons are with the tools the more smoothly the subsequent work will proceed.

In the SCOPE section users received an introduction to the equipment, so they know what they will be working with and, with larger systems, how they fit into the big picture. Training needs will vary, and depend on the degree to which users will be expected to operate the system. Generally, the smaller the computer, the more involved they have to be. At the Portland Archives and Records Center, for example, data entry clerks are fully trained on the word processing equipment they use for input. Once the data is transmitted 
to the county mainframe, however, the relationship changes. That computer is operated by trained professionals. All that PARC archivists require to run their programs is a list of commands to type into the terminal. It requires a basic knowledge of the system architecture, but very little technical expertise at all.

The PIC's first task, therefore, is to assess how involved participants will be, and then to evaluate what will be forthcoming from the vendor. Most small computers come with a tutorial program, usually a floppy disk that introduces the user to keyboard and to the machine's general capabilities. Some vendors have excellent training and support services while others have none. Even assuming they are good, chances are they won't accomodate the entire staff. Most will train only a few people as part of the purchase agreement, then it is up to those persons to teach everyone else. SYSTEM ORIENTATION has three components: an introduction to terminology through use of a Glossary, instruction on Operations and the Operating system, and finally instruction on the Application Software.

\section{Glossary}

Each participant should have a glossary of basic terms and concepts, such as hardware, software, operating system, utility, memory (RAM), storage (ROM), hard disk, floppy 
disk, tape (if applicable), file, record, menu, data disk, system disk, default, booting, formatting, CPU and disk drive. This can be a document that the PIC prepares him- or herself or it can be a published dictionary of computer terms. The only criterion for the latter is that it be simple enough for new users to understand. The advantage of the former is that it can be designed for a specific set of users and be in a notebook format that they can annotate or add to. The disadvantage of this option is that it means more work for the trainer who must prepare it.

Each term, ideally, is defined and then demonstrated in a training session. Some trainers have found that injecting some humor into the learning process is beneficial, especially for new users. They developed a computer Concepts Quiz to discuss with their students at the end of the session, reinforcing the definitions one more time. Some sample questions:

\section{COMPUTER CONCEPTS QUIZ}

1. CPU stands for:

a. The Central Processing Unit, or "brain" of the comptuer.

b. Computer Problems Unanimous, a national association of unhappy computer users.

2. RAM is:

a. A device used by unhappy computer users for getting even.

b. Random Access Memory, the workspace inside the brain of the computer. 
3. A FLOPPY DISK is:

a. A serious back ailment.

b. A sourdough pancake.

c. A plastic magnetic record on which the computer stores data and programs.

4. A HARD DISK is:

a. More serious than a floppy disk, possibly requiring surgery.

b. An ancient sourdough pancake.

c. Bigger, faster, and easier to work with than a floppy disk (also more expensive).

5. A CURSOR:

a. Marks your place on the CRT screen as you type into the computer.

b. An uninhibited computer user who expresses himself accordingly.

Figure 5. Computer Concepts Quiz, extracted from the

Junior League of Portland Computer Training Manual.

\section{Operations and the Operating System}

Next, the SYSTEM ORIENTATION instructs users about operations. They learn how to handle and care for floppy disks, how to use the printer, change ribbons, install and remove the tractor, and work with continuous form paper. They are handed a sheet of rules, like No smoking around the machine, no food or drink, and other basics.

Special attention is paid at this point to the Operating system (OS). This is one of the more confusing concepts for persons to learn, because they are conditioned to thinking of computers in terms of performing actual functions like word processing and calculating and don 't consider what it takes to make the machine run itself. 
Also, OS manuals tend to be written in more complex language and are harder to understand than most software guides. Often the best approach is to develop a one- or two-page summary defining what the Operating system is and setting out the most commonly used procedures. This gives participants the tools they need to move on, and they can return to the manual when they're more experienced.

The following guidelines were developed for an IBM-XT.

\section{IBM-XT DISK OPERATING SYSTEM}

The Disk Operating System, or DOS, is the set of programs that make the computer work. Without the DOS, it is an empty hunk of metal - the keyboard can't talk to the monitor, the monitor can't talk to the CPU, and the CPU can't talk to the printer. No application software can be loaded if the DOS isn't there to open the door and throw out the welcome mat.

The DOS is permanently stored on the fixed disk, also called the $\mathbf{C}$ Drive. When you turn the machine on, it will load automatically and then display the $\mathrm{C}$ prompt, which looks like this $\mathbf{c}>$, to indicate that it's ready to go to work. The computer will automatically store data on the hard disk unless you tell it otherwise. If you want to perform an operation on a floppy disk, you must redirect the system to the A Drive by typing

\section{A: + RETURN}

(all DOS commands are executed by hitting RETURN)

The machine will then display an A prompt, or $A>$. Just reverse the process to return to $\mathrm{C}>$.

In addition to providing the communicating links between hardware components, the DOS also has programs that perform houskeeping functions, called Utilities. The following Utilities are the ones you'll use most often. 
FORMAT. You cannot store data on a floppy disk until it is formatted. Formatting instalis certain instructions on the disk that enable it to communicate with the computer and receive information. To format a floppy, redirect the system to $A>$, insert the DOS disk, and type

\section{FORMAT + RETURN}

You will be instructed to remove the Dos disk and insert the disk to be formatted, then to strike any key. Hit RETURN again and the computer will format the Disk and tell you when it's through.

Formatting is also a way to erase a disk you want to re-use. It will clear off all your old files and prepare the disk to receive new data. Formatting can only be done from the A Drive.

DIRECTORY. To obtain a directory of all the files on a floppy disk, direct the system to $A>$ and type

\section{$\mathrm{DIR}+$ return}

Files will be 1 isted by name, followed by the number of bytes currently reserved for them on the disk. At the botton the directory tells you how man files are on the disk and how much empty space you have remaining. You can see a directory of the $C$ Drive as well by redirecting to $c>$ and typing the same command.

COPY. To copy files from one disk to another, first be sure you have directed the system to the prompt for the source disk. If your file is on the hard disk and you want to copy it onto a floppy, you should be in $\mathrm{C}>$. Then type

\section{COPY filename A:filename + RETURN}

The computer will copy the file and tell you then it's through. NOTE: if you already have a file by that name on the destination disk, the new file will replace the old one. If you want to keep the old file, give the one you're copying a new name, as follows:

$$
\text { COPY filename A:filename.a + RETURN }
$$


To copy from one floppy disk to another, direct the system to $A>$ and type

\section{COPY filename B:filename + RETURN}

The computer will instruct you to remove your source disk and insert your destination disk. The A Drive becomes the B Drive while the copying takes place.

DISKCOPY. To make a duplicate copy of a floppy disk, start in $\mathrm{C}>$ and type

\section{DISKCOPY A: B: + RETURN}

The computer will make the copy in several passes, taking data from $A$ :, storing it in memory, and then instructing you to insert your destination disk so it can copy the data on. You will probably have to remove and re-insert both disks several times. Just follow the computer's instructions. It will tell you when it is through.

ERASE To remove a file from a disk, just direct the system to the appropriate drive, and type

\section{ERASE filename + RETURN}

The computer will redisplay the prompt when it is through.

RENAME. To give an existing file a new name, direct the system to the drive where it resides and type

\section{RENAME filename newname + RETURN}

The computer will redisplay the prompt when it is through. A note about naming files: each file name can be 1-8 alphanumeric characters in length, and can have a 1-3 character extension. The file name and the extension are separated by a period.

Figure 6. Operating System Guidelines for IBM-XT, Junior League of Portland Computer Training Manual. 


\section{Application Software}

The final step in SYSTEM ORIENTATION is to introduce participants to the application software that will be used for the project, and help them become familiar with its functions, commands, and documentation. This is a gradual process, and users are not always totally confident when data entry begins, but time builds proficiency. At the outset, they need to study the documentation and complete any lessons or tutorials that are provided. This takes concentration, and ideally each person should have a succession of uninterrupted blocks of time to practice. The PIC guides users through this phase, teaching when necessary, then being available for questions when people are working on their own.

By the end of this last phase of SYSTEM ORIENTATION, participants should be ready to get started, and understand the instructions they will be given in the INPUT section. They should be able to solve simple problems, and be familiar enough with the documentation to know where to look for information. 
CHAPTER V

INPUT

INPUT, or Data Entry, contains all the materials pertinent to keying information into the computer. It is usually the largest section of a project manual and, indeed, is often segregated into a separate volume. Its functions include defining the data elements to be entered, telling the user how to enter them, and providing procedures and instructions for editing and updating the master file.

The governing axiom for assembling this part is the old phrase "Garbage In, Garbage Out." Computer output is only as good as what is keyed in. The automation process is preceded by a significant amount of planning. Definition of the problem to be solved or goals to be achieved is followed by an analysis of the systems (manual or automated) currently in place. This includes identifying the information collected and studying how it is processed and reported. The goal of automating, in most cases, is to improve on this process, either by making the work more efficient, or upgrading the quality and quantity of the output, or both.

As a result of system analysis, or needs assessment, 
one develops a list of information items, or data elements, and specifications for their use, that is, how they will be reported, how often, and in what form. If the product (output) is to be of any value, the input must be designed and implemented to meet those specifications.

A simple example: the Portland Historic Resources Inventory collected data on nearly 5000 properties. Reports could be generated from the entire data base but it was frequently more convenient to process it in smaller parts. The city was divided into ten geographical areas, each of which was given a code. How that code was keyed in was critical to getting the information out later. The code for a Near Southeast property, for example, had to be entered SE-A, not SE or SEA.

Input documentation helps to ensure that garbage does not go in, and that good useful data can be retrieved. One of the more challenging tasks the PIC will have is getting participants to use it. This writer has observed that data entry clerks are more apt, when they have a question, to turn around and ask the nearest person or simply enter what they think is right rather than look the answer up in their manuals. While this is frustrating, it is natural in that persons are accustomed to learning from their peers and tend to opt for human interaction when they have a choice. 
An important goal of INPUT training, therefore, is for participants to cultivate the habit of using their manuals. If persons understand that the logical requirements of the computer make this a necessity -- that is, these are not meaningless procedures -- they will cooperate. It is also important to emphasize that their contributions are valued, since the INPUT phase rarely begins with bug-free documentation. Each question should be approached by first referring to the manual. If the answer is found there, then the experience has reinforced its importance to the user. If the answer is not there, or needs clarification, the PIC can fix it and the user has an enhanced feeling of participation and teamwork. Whereas in the SCOPE and SYSTEM ORIENTATION sections participants were just learning, now they are developing expertise and, hopefully, confidence in what they are doing.

The INPUT section can be broken down into five general areas: Definitions and File Information, Data Base Design, Data Entry Instructions, File Updating, and Data Entry Controls. The first four are designed to progressively introduce the user to the data base, provide instructions for its creation, and set up a structure to ensure its continued quality. Data Entry Controls are developed by the PIC to monitor progress and detect problems before they become too advanced. 


\section{DEFINITIONS AND FILE INFORMATION}

This first part of INPUT is really a continuation of SYSTEM ORIENTATION, with the difference that participants receive information more specific to the project at hand. First, the PIC takes them through a review of the glossary to be sure they understand the language, with increased emphasis now on terms which are file related, such as data base, record, tag, field, data element, disk, and so forth.

This section also contains an information statement that relays the name of the project data file, where it resides, and discusses any special structural

characteristics it may have. This may be as short as a couple of paragraphs:

\section{Junior League of Portland}

Membership File Information

The JLP uses PFS:FILE electronic filing software to store data on its members. Information on Provisional and Active members is entered into a data base called PROFILE, which resides permanently on the fixed disk, and is also backed up on two floppy disks. PROFILE is illustrated in the Data Base Design Section of this manual.

Access to PROFILE is obtained from the $\mathrm{C}$ Drive. Direct the system to $C>$ and type

\section{FILE + RETURN}

The computer will display the PFS:FILE menu and you are ready to begin. Step by step procedures are provided in Data Entry Instructions.

Figure 7. File Information, Data Entry Instructions and Style Manual, JLP Membership Information System. 
Clearly, the above example is for a very simple system and needs to convey only the name of the data file and where it can be found. A File Information statement for a SPINDEX data base would have more substance:

Portland Archives and Records Center Historic Resource Inventory File Information

Information collected by the Portland HRI will be stored and processed on the city/county computer using SPINDEX data base management programs. Data will be entered on WANG word processors at PARC and then transmitted to the Data Processing Authority (DPA) via telephone line. Each file is transmitted with a half dozen lines of information called Job Control Language (JCL) that identify it to the computer and tell it to hold the file on a disk until it receives further instructions.

Also on disk at DPA is a copy of the HRI Master File, which contains all the property information that has been transmitted and processed so far. This file's name is:

\section{PAIA.THRI02-}

The PAlA is PARC's account number. The THRl02- is the file's name. The last digit can be anything from 0-9 and is assigned by the archivist when the file is updated.

For example: a new batch of property profiles is transmitted, and the computer holds it on disk until the archivist submits the program that merges it with the master file. The computer is instructed to read the old Master File, THRl02l, integrate the new data, and then create a new Master File with the name THRl022. This way the archivist can retain a copy of the old file in case there are problems with the new one.

The computer holds a file on disk for seven (7) days following its last use, after which it is automaticaly scratched by DPA. To save the file for a longer period, it must be stored on tape. Procedures for tape storage are found in the Operations and Maintenance section of this manual.

Figure 8. File Information, Historic Resource Inventory SPINDEX Operations Manual. 
File Information is useful for two reasons. Not only does it describe the processing structure for the data entry staff, but it also records it for future PICs. No one should assume that he or she will be around for the entire life of a data base, and it is important to document details like assigning file names and and the need to secure disk back-ups.

\section{DATA BASE DE'SIGN}

While planning for the automation project, the archivist has decided what items of information will be included in the data base. These have been arranged in categories and subcategories and placed in a format the computer will recognize. The Data Base Design section describes this format.

The smallest possible information item is called a data element. A field is composed of one or more data elements, sometimes called subfields. For example, when describing a collection one records its Beginning Date and Ending Date these are each data elements. Inclusive Dates, however, is a field which contains them both. All the fields pertaining to any one collection are gathered into a single set called a record. They are distinguished from other records by a unique identifier, often called a control number.

Data base designs vary in size and complexity depending 
on the system in use. A simple example is PFS:FILE, a software package used on IBM personal computers, which collects data just like a form. The user decides what information he wants, types the form headings on the screen, and starts keying in. At the opposite end of the spectrum is the MARC format. MARC stands for Machine Readable Cataloging, and was first developed to describe library materials. Now a compatible format has been developed for archive and manuscript records so they can be made available to researchers through library information networks. A data base design in the MARC format allows the archivist to create a complex structure of fields and subfields and use them in a variety of different records, depending on the situation.

The purpose of the Data Base Design section is to convey the concept of the data base, a wide-angle view, so that participants can see its overall structure and composition. To this end, it provides a data summary and illustrates the record format or formats.

\section{Data Summary}

Each item of information is collected and processed for a purpose, and during the planning process each data element is carefully defined, usually in a detailed format description or a data dictionary. These documents can be lengthy and 
complex, and are excellent for reference purposes, but they don't give the user an overall picture of what the data base looks like. The Data Summary does this at a glance by listing the fields, titles only, in the order in which they appear in the format. Where applicable, each field is accompanied by the numerical tag which identifies it to the computer. For example:

\section{Historic Resource Inventory SPINDEX Data Base Design}

$000 \quad 52720 \ldots-\ldots-13$ Control Number

110 Master File Number

120 Street Address

140 Legal Description

150 Quarter Section Map Number

160 Neighborhood Association

170 Neighborhood Quadrant

250 Original Name

$26 \mathrm{x}$ Other Name(s)

$28 \mathrm{x}$ Original Function(s)

29x Other Function(s)

300 Date Built

$32 \mathrm{x}$ Style

$33 \mathrm{x}$ Architectural Plans by

$34 \mathrm{x}$ Contractor(s)

$35 \mathrm{x}$ Original Owner(s)

$36 \mathrm{x}$ Other Owner(s)

$37 \mathrm{x}$ Tenant(s)

410 Tax Assessor's Account Number

420 Zoning Designation

$46 \mathrm{x}$ site of

$47 x$ Original Features Remaining

480 Site Now Occupied by

500 Rank

$5 \mathrm{~lx}$ Designation(s)

530 Historic District

540 Special Features/Materials - Original Remaining

550 Special Features/Materials - Original Removed

560 Special Features/Materials - Significant Alterations 
$57 x$ Areas of Significance

$60 \mathrm{x}$ Statements of Significance

$62 \mathrm{x}$ Bibliography

63X Old Address(es)

640 Original Building Permit Number

65x Major Alteration Date/Permit/Architect

$70 x$ Present Owner(s)

710 Present Owners' Mailing Address

$75 \mathrm{x}$ Preservation Funding

800 Inventory Photo Negative Number

$85 \mathrm{x}$ Name Index

$86 \mathrm{x}$ Corporate Index

$87 \mathrm{x}$ Subject Index

Figure 9. Data Summary, Historic Resource Inventory SPINDEX Data Entry Instructions and Style Manual.

If the design includes subfields as well as fields, the list might look more like this:

Smithsonian Institution

Bibliographic Information System (SIBIS)

Draft Data Base Design for Circulation Module

$\begin{array}{ll}\text { NNN } & \text { User Registration Number } \\ \text { NNN } & \text { Registration Date } \\ \text { NNN } & \text { Archives Unit ID } \\ \text { NNN } & \text { User Name } \\ & \text { \$A Last Name } \\ & \text { \$B First Name } \\ \text { SC Middle Name } \\ \text { NNN Institutional/Business Affiliation } \\ \\ \text { \$A Smithsonian Staff (Y/N) } \\ \text { \$B Organization Name } \\ \text { \$C Department } \\ \text { \$D Position/Title } \\ \text { \$E Name of Supervisor/Advisor } \\ \text { \$F Degree Sought } \\ \text { \$G Institution Type } \\ \text { Address } \\ \text { \$A Building/Room Number } \\ \text { \$B Street Address } \\ \text { \$C City } \\ \text { \$D State } \\ \text { \$E Zip Code }\end{array}$




$$
\begin{aligned}
\text { NNN } & \text { Telephone } \\
\text { NNN Identification } & \text { \$A Type of Identification } \\
& \$ B \text { Identification Number } \\
& \text { NNN = Numerical tags unassigned }
\end{aligned}
$$

Figure 10. Extract, Proposed Format for SIBIS

Circulation Module, Smithsonian Institution.

\section{Record Format}

Record formats are illustrations of what the user will actually see when he or she gets ready to enter data. While the previous section lists all the fields in the data base, it's quite likely they won't all be used at the same time or even entered in the same order.

While the SPINDEX data base design illustrated in Figure 9 was arranged in that particular tag order for reporting purposes, the data entry format was designed to accomodate the order of the inventory form, which was designed for the convenience of the researchers. It looks quite different, and having a picture of it considerably reduced confusion among the data entry clerks.

\section{HRI Input Record Format}

000 Control Number

110 Master File Number

120 Street Address

160 Neighborhood Association

170 Neighborhood Quadrant

530 Historic District 
410 Tax Assessor's Account Number

140 Legal Description

150 Quarter Section Map Number

420 Zoning Designation

700 Present Owner(s)

710 Present Owners Mailing Address

$63 \mathrm{x}$ old Address(es)

250 Original Name

$26 \mathrm{x}$ Other Name(s)

$28 \mathrm{x}$ Original Function(s)

$29 \mathrm{x}$ Other Function(s)

300 Date Built

$33 x$ Architectural Plans by

$34 \mathrm{x}$ Contractor(s)

$35 \mathrm{x}$ Original Owner(s)

$36 \mathrm{x}$ Other Owner(s)

$37 \mathrm{x}$ Tenant(s)

640 Original Building Permit Number

$65 \mathrm{x}$ Major Alteration Date/Permit/Architect

540 Special Features/Materials - Original Remaining

550 Special Features/Materials - Original Removed

560 Special Features/Materials - Significant Alterations

$62 \mathrm{x}$ Bibliography

$32 \mathrm{x}$ style

$51 x$ Designation(s)

$57 x$ Areas of Significance

$75 x$ Preservation Funding

800 Inventory Photo Negative Number

Figure 11. Record Format, Historic Resource Inventory SPINDEX Data Entry Instructions and Style Manual.

This format was used for standing properties only - another one was required for sites of buildings no longer extant. For simple systems, the Data Summary and the Record Format might be one and the same, and a single illustration will suffice. The point is to give the user all the tools he or she needs to become familiar with the design and avoid confusion when its time to start entering data. 


\section{DATA ENTRY INSTRUCTIONS}

Data Entry Instructions are the step-by-step procedures for keying information into the data base. To assemble this section, the PIC picks up a number of threads already woven into previous parts of the manual. First, during SYSTEM ORIENTATION users were introduced to the application software and spent a prescribed amount of time practicing with it and reading the documentation. They have reviewed terminology and learned the name and location of the data file they will be working with. Finally, they were shown what the overall data base design looked like. Now the PIC adds field-by-field instructions for entering the data. While planning the project, the archivist defined fields in a data dictionary or format description. This document lists each field in the data base and defines its contents and limitations. It is shaped by information needs, i.e. what data must be collected to satisfy a certain requirement, and by reporting needs - how that data will appear in final form. The Data Entry Instructions translate this information into specifics. They dictate what data is to be entered into each field, how it should be entered, and whether or not there are limits to its length. The following is an extract from the Portland HRI project manual : 


\section{Historic Resource Inventory \\ Data Entry Instructions}

$000 \quad$ Control Number

Example: (for 620 S.W. Fifth Avenue)

$52720100500620 / 3$

Enter control number without spaces between digits.

The control number is assigned by the archivist. Detailed instructions are found in Appendix 1. The first five digits are always the same: 52 is the numeric code for Multnomah County, 720 represents the City of Portland.

The sixth digit indicates whether or not the property is on a named or numbered street in a given quadrant of the city.

Digits 7-9 represent the street name or number. For named streets, a three-digit code is obtained by using 1000 Characters of the Alphabet. Broadway, for example, is represented by the number 1ll. Numbered streets are indicated by the actual street numbers, with leading zeros where necessary. Fifth Avenue is represented by 005, Tenth Avenue by 010 .

The last five digits represent the numeric street address and consist of the actual building number with leading zeros where necessary. Example: 00620, 01341 , or 18527 .

The control number is always followed by a $/ 3$ to indicate SPINDEX level 3. There are four positions remaining to be used for a level 8 trailer when the number of fields for a given record exceeds 50 .

110 Master File Number

The master file number consists of the last nine digits of the control number with hyphens inserted between the quadrant, street, and numeric address designations.

Example: 1-005-00620 
$120 \quad$ Street Address

Enter street address. Do not space between quadrant designators but follow each initial with a period (S.W. not SW). All street names and numbers are to be spelled out completely. Do not abbreviate street, avenue, etc.

Example: 620 S.W. Fifth Avenue 1130 S.E. Hawthorne Boulevard 819 S.E. Thirty-fifth Avenue

26x Other Names

Enter in any order, using consecutive tags as needed. The "x" at the end of the tag means that a field may contain multiple entries. The " $x$ " is replaced by a single digit (0-9) or an alpha character $(A-Z)$, providing 33 possible entry tags (do not use the letters I, O, or Q).

Example: 260 Wilcox Building

261 Williams Building

$26 \mathrm{~A}$ Sherlock Building

26B New Market Theater

$32 x$

Style

Use terms provided on list of styles and Typologies in Appendix 3. Use consecutive tags as needed.

Example: 320 Twentieth Century Classical 321 Streetcar Era Commercial

$54 \mathrm{x} \quad$ Special Features/Materials $=$ Original Remaining

Enter in pargraph form. Limit pargraphs to 986 characters, approximately 14 lines. Continue text with consecutive paragraphs if necessary.

Figure 12. Extract, Data Entry Instructions, Historic Resource Inventory SPINDEX Data Entry Instructions and Style Manual. 
The goals of Data Entry Instructions are to make the process as simple and straightforward as possible and to promote data quality. The computer can be a big help in achieving these ends. Many machines can now be programmed to prompt the user to enter specific information at specific times, which means he or she doesn't have to struggle with remembering which numerical tag stands for which field.

Also, more and more software packages are being developed to accomodate built-in thesauri. In Figure 12, note that the data entry clerk is referred to an appendix when entering the $32 \mathrm{x}$ field for architectural style. This is an authority list of acceptable terms that must be keyed in exactly as they are given. Consistency is necessary to produce clean indexes. Entering "Twentieth Century Classical" for one building and "20th century Classical" for another means that properties of that style will be indexed under two headings instead of one, a situation to be avoided. Futhermore, the researcher wishing to search a data base for all buildings of that type will get incomplete results if the term hasn't been entered consistently. To have such authority lists in printed form is better than nothing at all, but newer software packages will direct the computer to check such terms itself. If something has been entered the wrong way, the machine will display an error message. 
Whatever the system and its requirements, the PIC uses Data Entry Instructions to tell participants what to do and what to expect. Preparing such guidelines requires a concentrated effort at the outset, developing procedures and anticipating stylistic needs, but having them saves countless questions and time spent backtracking to check on how something was entered previously. Data entry is the most time consuming, labor-intensive, and expensive activity in a project. Any tool that will reduce the need to edit or verify input will contribute to speeding work up and keeping costs down.

FILE UPDATING

File Updating activities are those pertaining to making additions or corrections to, or deletions from, the data base. It means different things to different systems, and the PIC's first task is to define it for the project at hand. Updating an on-line file can be as simple as calling up a record, making a change, and storing it away again. A batch processing system requires the extra steps of creating a second file of addition, correction, or deletion records and then running the program that merges it with the master file.

File updating begins with the master file, which is the entity on which actions are performed. These fall into 
three categories: 1) making corrections to existing records as a result of the editing process, 2 ) adding new records to the data base, and 3 ) deleting obsolete records. The PIC must set up a structure that enumerates and controls the activities involved in effecting these changes. These include developing editing guidelines, designing change control forms and instructions, and keeping track of what changes have been made.

\section{Editing}

No matter how conscientious and careful the data entry clerks are, they do make mistakes, so input is proofed and edited. This is also a useful practice when training new employees because it allows the PIC to detect whether or not persons are using and understanding the Data Entry Instructions. The PIC can prevent editing from becoming a time consuming activity by establishing some basic guidelines and by working with draft reports.

Fields are collected into a data base design for different reasons and are reported in different ways. They are divided roughly into two categories - those which are sorted and those which are not. Included in the former are fields used to build indexes or break the master file down into smaller submasters, as the Historic Resources Inventory data base is subdivided by geographical area. Non-sorting 
fields are descriptive, and generally appear as secondary, background information in reports.

While it is desirable for the data base to be as error free as possible, the sorting fields receive primary attention in the editing process, and the guidelines should reflect this focus. Furthermore, data can often be checked much more quickly by running drafts of actual reports than by trying to proof records one by one. If an index term has been entered inconsistently, it will show immediately when the index is printed whereas it might be difficult to spot by examining added entries in each individual record.

If, on the other hand, the record sees a lot of use in its entirety, then proofing each one is advisable. The Junior League, for example, has used PFS:FILE to produce a data form for each member. While certain fields are more important than others and are checked from special indexes, the membership record itself is used by several personnel committees and efforts are made to see that it is accurate. It is up to the PIC to design an editing process that serves the project's ultimate reporting and information needs.

Change Controls

Once the need for an addition, correction, or deletion has been identified, it must then be effected. Depending on 
the system in use and the number of participants involved, the PIC may choose to set up a process to record and control these changes. This becomes more practical the more users a system has.

One of the simplest and most useful tools for recording changes is a "dump" of the data base. This is a printed report in which the computer spills out all the contents of a given file, record by record. When additions, corrections, and deletions are made, the PIC can note them on the dump and thus keep an up-to-date log of what is in the master file.

If a data file is particularly active and changes are submitted by a number of persons or departments, then change Control forms make the process more orderly, especially for the data entry clerks. They also make it possible for the PIC to review and $\log$ all modifications. The simplest kind of form is the printed copy of the record itself, marked with the desired corrections. This is most practical when the record is used in its entirety, but in many cases it is not - participants determine the need for additions, corrections, or deletions in the process of carrying out routine functions.

In such cases they must have a change Control form that they can fill out and submit for data entry. This form must do three things: first, it must have a space to enter a 
record's identifying name or code. Second, it must have subsequent spaces for each field, so that the appropriate corrections can be filled in. Finally, it must instruct the user on how the form is completed.

For example, the Portland Archives and Records Center (PARC) was involved in a project with the Portland Bureau of Traffic Engineering (BTE), in which a SPINDEX data base was created to control publications in the Bureau's reference library. PARC's records management staff conducted an initial inventory, did all the data entry, and produced a register and index for use by BTE engineers. Thereafter it was up to them to keep track of additions and corrections to the collection. They were provided with BTE Library Cataloging Forms and instructions on how to complete them for each of the following scenarios: adding a new title, changing information in an existing entry, and deleting an existing entry when a title is removed. These forms were batched and sent to PARC once a year. Records management staff updated the data base and produced new reports and the process began anew. Figure 13 illustrates the form and the instructions for changing an existing entry. 


\section{PORTLAND BUREAU OF TRAFFIC ENGINEERING \\ LIBRARY CATALOGING FORM}

Complete one form for each item. For questions of how a new field should be entered (form, style, etc.), consult Data Entry Instructions on pp. 5-6.

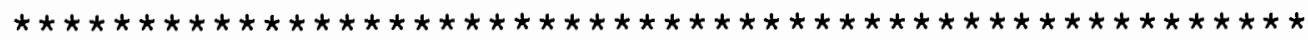

New Entry

Deletion

Change

000 Control Number: $\overline{c l} \overline{\mathrm{ass}} \overline{\#}-\overline{\text { work }} \overline{\#}$

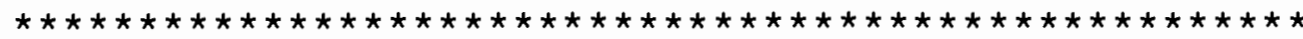
120
Title
A $C$
D

200

Date

A $C$

D

500

Author

A

C

D

600 Added Subject Terms

A C D

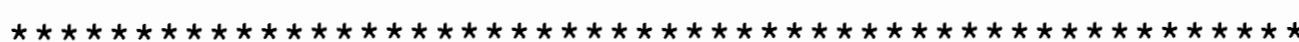




\section{Changing an Existing Entry}

Check the space next to Change.

Enter the classification number in the first 4 spaces of the Control \# line. If the classification number has more than four characters (100 T7), drop the extra digits.

Fill in the last 4 spaces of the Control \# 1 ine with the work number, obtained from the Work Number Report immediately following this section. This report is arranged by classification number. Find the pertinent title and record the work number, which is in the right-hand column. Where this number is only 3 digits, add a leading zero.

When changing an existing entry, fill in only those fields in which a change occurs. Next to the field title, circle the appropriate field action code:

A If the field has been empty and is being added to for the first time.

C If the data in the field is to be replaced with new data.

D If the field is to be deleted entirely.

When adding (A) or changing (C) a field, write out the entire entry in the space provided. For example, when correcting a typographical error in a title, write out the entire title, even if the correction only involves one word.

If the field is to be deleted entirely (D), the entry need not be recorded - just circle the action code. If, however, there is more than one entry for a field and you only want to delete one, circle D and write that entry in the space provided.

Figure 13. Extract, Change Control, Bureau of Traffic Engineering Library Reference Guide and Updating Procedures Manual. 
As a whole, the File Updating section is a collection of directives and procedures that describe how the master file is updated in various stages and then provide more detailed information where necessary. If, for example, the PIC intends to edit from reports, the guidelines must refer the user to the particular report profile in the OUTPUT section that will tell him or her how to produce it. Once the report is in hand, the guidelines provide instructions for checking it to be sure the data meets certain standards.

If there are changes, the user is referred to the Change control form to submit an update to the master file. Finally, the data entry clerks receive these corrections and transform them into an actual update, either by following instructions in the software documentation or procedures developed by the PIC.

File Updating includes policy statements as well, especially when there are many users contributing changes. Someone must see to it that they are all valid and conform to the style guidelines dictated in the Data Entry Instructions. In Figure 1, the Project Introduction for the Historic Resource Inventory, it was stated as a matter of policy that all changes to the data base had to be cleared by the Inventory Coordinator or the City Archivist. This became necessary after the project got some publicity, and persons started calling in to request that their houses be 
added to the master file. PARC staff were able to tel them that all input had to be submitted by inventory

professionals. Clearly, the nature of the policy depends on the project and its goals and products, but File updating is a key phase for controlling the quality of the data base.

\section{DATA ENTRY CONTROLS}

In the project's planning and early implementation stages, the PIC began developing a work plan that defined the goals and objectives and enumerated the activities that had to be carried out to meet them. Functions are performed by staff persons according to a specified schedule, and certain amounts of money have been budgeted to support their activities. Controls are a way of monitoring progress and spotting problems before they get out of hand. They are also an excellent record for the PIC to use to project time, staff, and budgetary requirements for future activities.

A simple Data Entry Control Chart is illustrated in Figure 14: 
$\frac{\text { Junior League of }}{\text { Data Entry Control } \frac{\text { Eort and }}{\text { Chart }}}$

\begin{tabular}{|l|l|l|l|l|l|} 
Date & $\begin{array}{c}\text { Operator } \\
\text { Name }\end{array}$ & $\begin{array}{c}\text { Starting } \\
\text { Name }\end{array}$ & $\begin{array}{c}\text { Ending } \\
\text { Name }\end{array}$ & $\begin{array}{c}\text { \# of } \\
\text { forms }\end{array}$ & Time \\
\hline & & & & & \\
\hline & & & & & \\
\hline & & & & &
\end{tabular}

Figure 14. Data Entry Control Form, Data Entry Instructions and style Manual, JLP Membership Information System.

At the Junior League membership information is entered from an alphabetical card file. Because the job is being done by more than one person, starting Name and Ending Name tell each data entry clerk where the previous person has stopped. Counting the number of forms entered and recording the time it takes help the PIC gauge how long it takes to enter one form and then project how long it will take to do the whole job. Also, if it is evident that one person is slower than the others the PIC can give him or her extra attention.

If the budget has to be watched closely, more columns can be added to track costs. At the Portland Archives, for example, every hour of staff time spent on a given project had to be tracked, so the PIC had columns for Number of Hours Worked, Hours X Wage, and Cumulative Wage Expenditure. 
It was possible to look at a chart for any project and know how much of the personnel budget had been spent.

Controls can also be turned to good use as morale boosters. The data entry for the 5000 properties in the Portland HRI seemed an overwhelming task, so the Archivist designed a wall chart where clerks could record their progress. As this was logged in day after day, persons could see how the task was advancing and they became more motivated to finish the job.

In developing controls the PIC must determine what information he or she wants to monitor from day to day or week to week and then design the appropriate chart or forms. The larger the project, the more useful controls are for tracking its progress. 
CHAPTER VI

OUTPUT

Just as INPUT helps the user key data into the computer, OUTPUT helps him or her manipulate that data and get it back out again in a usable form. There are many different types of output: the user can have information displayed on the screen for quick reference or printed out if a more permanent copy is required. Output can also be printed directly onto microfilm or transmitted to another computer.

Every software package is designed to make the computer receive and store data according to certain specifications, but these functions are all preparatory to the primary one of then manipulating that data to produce specific results. The OUTPUT section is designed to help the user generate the desired products of the project. In keeping with the trend of starting with the descriptive and following up with more technical information, OUTPUT begins with a Report Inventory. This is a listing of all the reports required for the project, each one briefly described and illustrated. It is followed by Report Profiles, which are more detailed and provide instructions for each report's production. The 
OUTPUT section concludes with Reporting Controls, which help the PIC keep a record of what has been produced when.

\section{Report Inventory}

The Report Inventory is a reference document for project participants, intended to give them enough information to know what report they want to produce and then guide them to the more specific Report Profile. The following is a sample as it would appear for the Portland Historic Resource Inventory (HRI):

\section{Sample HRI Report Inventory}

Report Title: Description:

Output:

Frequency:
HRI Chronological Index

Programs extract report fields from the master file into a submaster, identify indexing field or fields, then sort and produce a listing of properties in order of date built. Keyword is Date Built ( 300 field). Secondary report fields are Master File Number (110), Address (120), and Neighborhood Quadrant (170). on request.

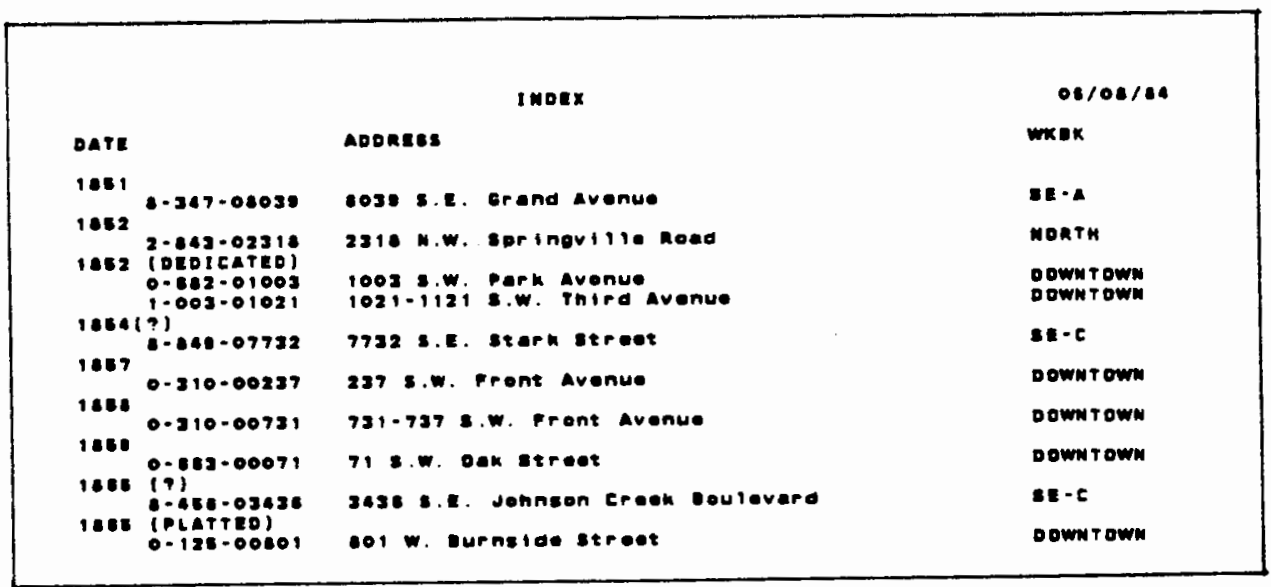


Report Title: Description:

Output:

Frequency:
HRI Master File Checklist Programs extract report fields from master file into submaster, then print them in control number order to list all the properties in the data base. Can also be used to list all the properties in a given district or quadrant - must then be preceded by THR29.

Register listing of Master File Number (110) and Address (120). on request.

\begin{tabular}{|ll|}
\hline & \multicolumn{1}{c|}{ HRI MASTER FILE NUMBER CHECKLIST } \\
MSTR FILE\# & ADORESS \\
& \\
$4-716-04780$ & $4780 \mathrm{~N}$. Princeton Street \\
$4-716-04925$ & $4925 \mathrm{~N}$. Princeton Street \\
$4-716-05525$ & $5525 \mathrm{~N}$. Princeton Street \\
$4-744-06636$ & $6636 \mathrm{~N}$. Richmond Avenue \\
$4-751-06937$ & $6937-6941$ N. Roberts Avenue \\
$4-774-06837$ & $6837 \mathrm{~N}$. Saiem Avenue \\
$4-779-02409$ & $2409 \mathrm{~N}$. Saratoga Street \\
$4-822-10000$ & $10000 \mathrm{~N}$. Simmons Street \\
$4-822-12000$ & $12000 \mathrm{~N}$. Simmons Road \\
$4-831-07320$ & $7320 \mathrm{~N}$. Smith Street \\
$4-831-07332$ & $7332 \mathrm{~N}$. Smith Street \\
$4-831-07406$ & $7406 \mathrm{~N}$. Smith Street \\
\hline
\end{tabular}

Figure 15. Sample Report Inventory, compiled from Historic Resource Inventory SPINDEX Operations Manual.

If many different reports are generated for a project, the PIC has the option of preparing a table of contents or index by name and function to help participants find what they're looking for a little faster. Also, if a report is routinely produced for the public, the inventory should also include its cost. 
Report Profiles

Once the user has determined the need for a specific product, he or she turns to the Report Profile to find out how to run it. Producing reports may be easy or difficult, depending on the system in use. It is the PIC's job as a facilitator to set them up in advance, test them, and make the profiles as straightforward as possible. Users seeking information in the course of carrying on day to day business need to be able to get it fast and without problems. If they experience difficulties, they are apt to go back to their "old, reliable" manual systems and the data base will be underused.

Report Profiles contain the following information:

Report Title:

Job Stream Name:

Report Purpose:

Program Components:

JCL:

Output: the actual title that appears on the report.

the name of the file or command the user must enter to execute the job.

a brief statement about why the report is produced.

the different programs that are executed to produce the report. This category is not always required for simpler systems.

an illustration of the Job Control Language that is submitted to the computer to make the job run. Again, not always needed for simpler systems.

specifications as to how the report will appear in final form - will it be printed, held in a data file for further processing, transmitted to another location, etc. 
Instructions:

information the participant must have in order to submit the job.

The following is an example of a Report Profile as it would appear for the Portland Historic Resource Inventory, using the above model:

Report Title:

Job Stream Name:

Purpose:

Program

Components :

Output:

Instructions:
HRI Area Submaster

THR29

To create a submaster from the HRI master file according to specific geographic parameters.

Refer to JCL illustration below.

1) Execute HR71, which searches HRI master file THRlo20 ( line //HR7101, DATA IN) for qualifications specified in parameter cards SPIN3PGA and B, and identifies the control numbers of the records that meet the requirements (//HR7103, THR7101, SELECTED DATA).

2) Execute HR75, which takes the CONTROL DATA selected above (THR7101) and runs it against the MASTER IN (THRI020) and copies all the records whose control numbers were identified in the previous step, creating a new submaster (//7503, THR7517 SELECTED DATA).

Because creation of this submaster is an intermediate step preliminary to running another job of the selected submaster, it is not printed out, but saved in a disk file named THR7517.

1) Be sure the most current master file number is entered in lines //HR7101 and //HR7502. Obtain from Job Control Register. 
2) In Control card SPIN3PGA, the 170 stands for the field on which the extract will be based, in this case the Neighborhood quadrant. The 04 stands for the number of characters in the field, and is followed by its contents. Enter the following parameters depending on which area you want to extract:

$\begin{array}{ll}08 & \text { DOWNTOWN (Downtown) } \\ 02 & \text { NW (NW Portland) } \\ 04 & \text { SW (SW Hills) } \\ 04 & \text { SW-A (Far SW) } \\ 05 & \text { NORTH (North Portland) } \\ 04 & \text { NE (Near NE) } \\ 04 & \text { NE-A (Far NE) } \\ 04 & \text { SE-A (Near SE) } \\ 04 & \text { SE-B (Mid SE) } \\ 04 & \text { SE-C (Far SE) }\end{array}$

3) The job will execute and create a separate disk file called THR7517 which then becomes the DATA IN or any further jobs.

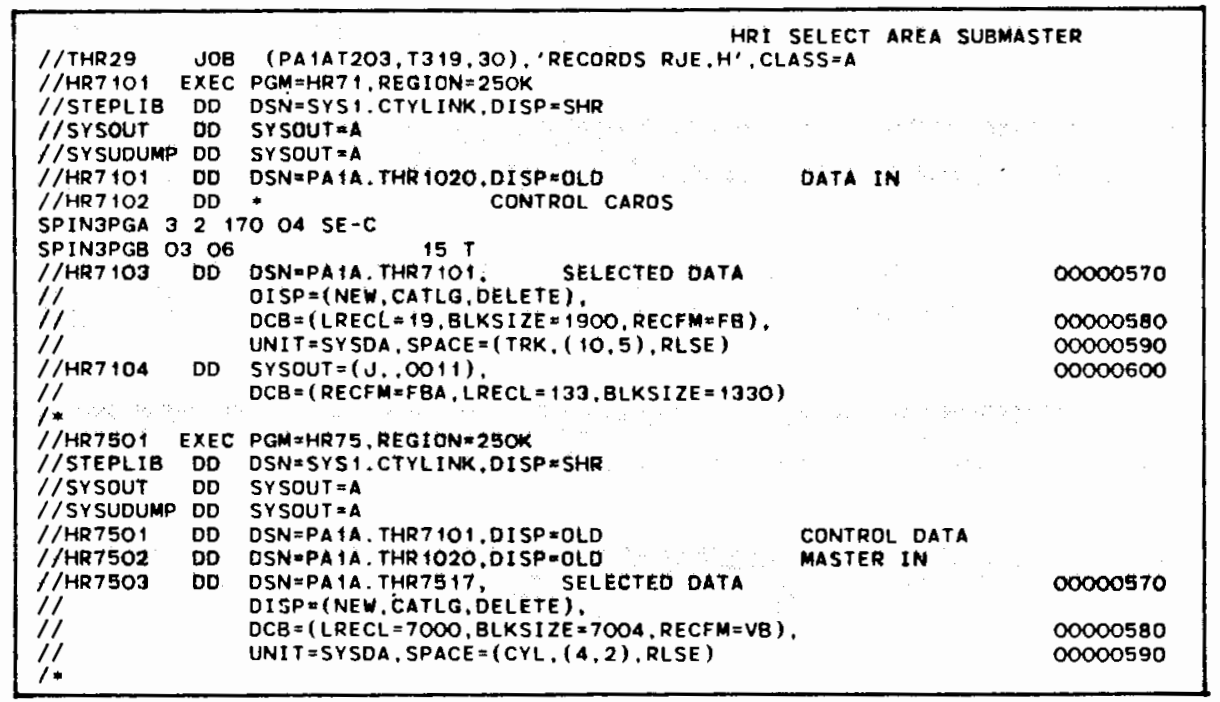

Figure 16. Sample Report Profile, compiled from Historic Resource Inventory SPINDEX Operations Manual. 
The previous example is for a complex system that is not consistently documented, so it is necessary for the PIC to provide a lot of explanation, illustration and instruction along the way. In contrast, a Profile using PFS:REPORT is much simpler in scale, and the user can be guided to appropriate sections in the software manual without difficulty.

Report Title: Job Stream Name: Purpose:

Output:

Instructions :
JLP Active Master List

ACT IVES

To print an alphabetical list of JLP active members, with their current volunteer placements, placement advisor names, and sustaining dates.

Printed, 125 column width; insert green-bar paper in printer.

\section{1) in C> type REPORT + RETURN}

2) When REPORT menu appears, enter: SELECTION NUMBER: 1

FILE NAME: PROFILE Press Flo.

3) Enter Retrieve Specifications using guidelines on pages $1-5$ through l-ll in the REPORT manual. Press Flo.

4) Enter Report Options as follows:

TITLE: ACTIVE MASTER LIST

PRE-DEFINED REPORT: ACTIVES

OUTPUT TO: COMI

LINES PER PAGE: 66

PAGE WIDTH : 125

Press Fl0. The report will be processed and printed.

Figure 17. Sample Report Profile, compiled from Junior League of Portland Computer Operations Manual. 
In the above example, the software allows the PIC to pre-define eight reports for each PFS file. The only specifications the user has to enter are those which retrieve the forms to be included in the report. The PFS:REPORT documentation is very clear on how this is done, and does not need repeating. In this case the PIC is simply giving the report production process an instructional shape, telling the user where to go to achieve the desired results, and making the process a little faster than it would be if the user had to start from scratch and search the documentation every step of the way.

Having Report Profiles as a reference can improve the user's attitude towards the computer and make him or her more confident about approaching it with a specific job. It also saves the PIC the time that would be spent giving advice and guidance to users who aren 't sure what to do. Moreover, it promotes efficiency and supports the consistent generation of a quality product.

\section{Reporting Controls}

There are two kinds of Reporting Controls: a Job Control Register, which is a record of all the output produced for a project, and a Project Control Chart, which tracks the activities required to achieve a specific product. The Job Control Register is a reference for what 
was done when, and logs job numbers, master file numbers, routine maintenance activities, and whatever else the PIC wants to record. It is especially useful for large projects with many clients or uers where the PIC may have to monitor the volume of reports produced by each one or have a way of checking to be sure a report was generated when it was supposed to be.

Figure 18 is an illustration of a Job Control Register that was kept for the Portland Historic Resource Inventory. It tells us that the master file was updated with a batch of new data, that a Near Northeast (a section of Portland) submaster and master file checklist were run, and that a tape back-up of the new master file was made. Since files are only kept on disk for seven days at the Data Processing Authority, it is important for the PIC to be able to look and see when a file was last used and when the last back-up was created. The Register was also used to keep a running tally of the number of properties in each geographical area, so each time a submaster program (THR29) was run, the count for the area was recorded.

The other kind of Reporting Control is a Project Control Chart. This is a useful tool in large projects when there are a lot of steps involved in achieving a specific product. It spells out the activities, one by one, for participants, and helps prevent steps from being left out. 
Figure 19 is an illustration of a Control Chart that was developed for the last phase of the Portland HRI. A prescribed set of steps (in the Activity column) had to be carried out for each geographical area (across the top of the page) in order to edit and deliver copy for a final publication. Using this chart, the PIC could tell at a glance where each area stood, what was behind schedule and what had been completed. 


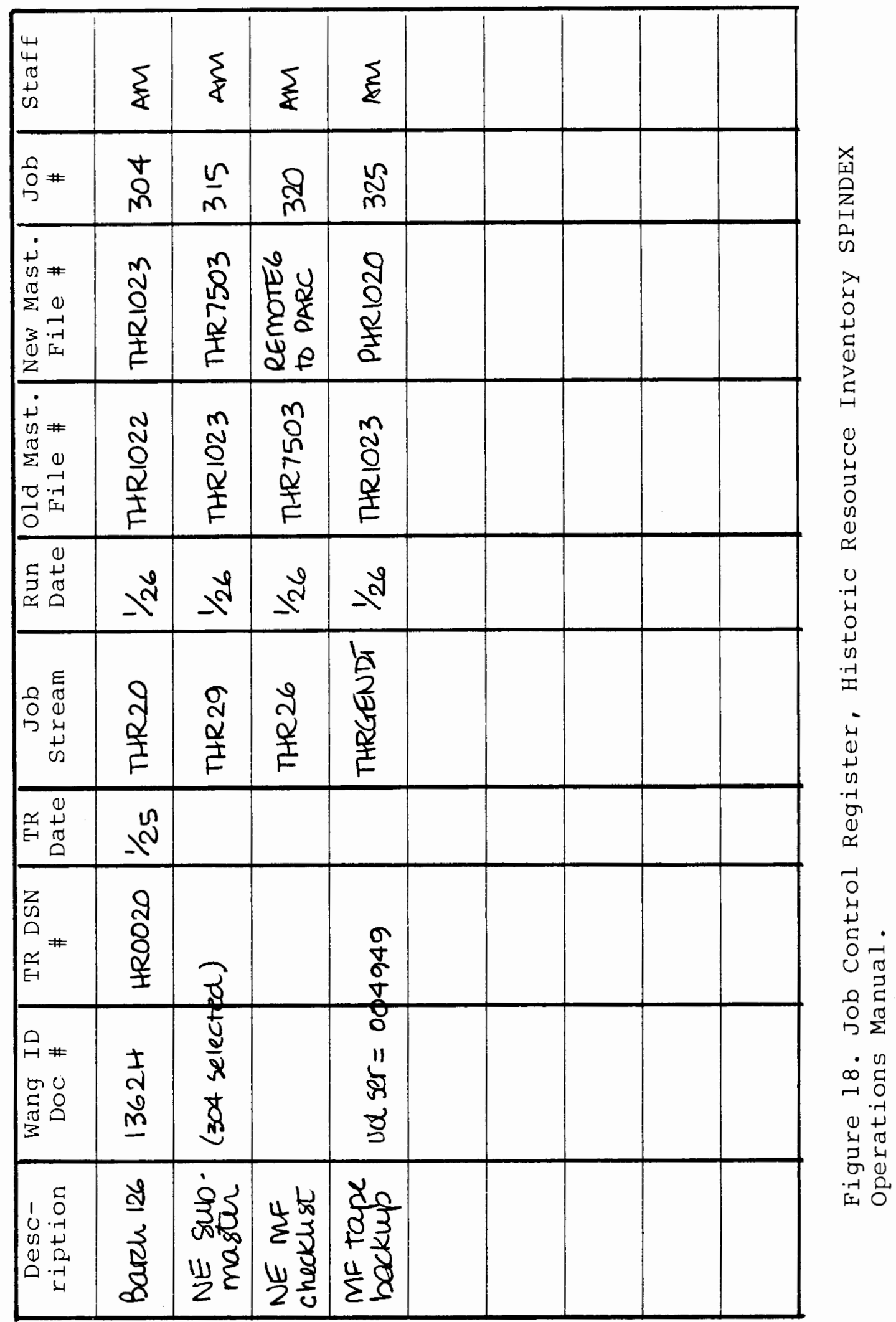




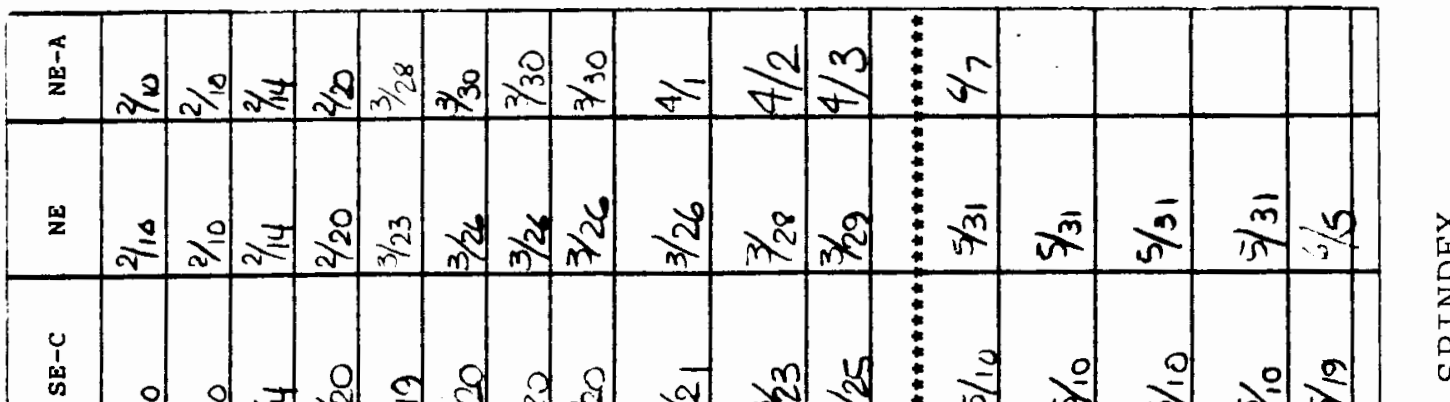

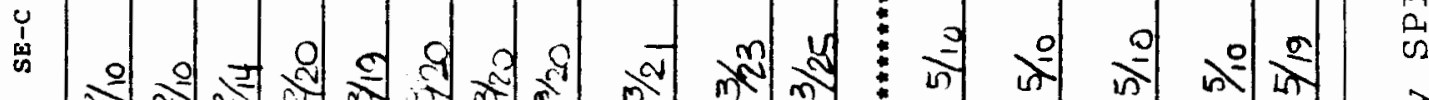

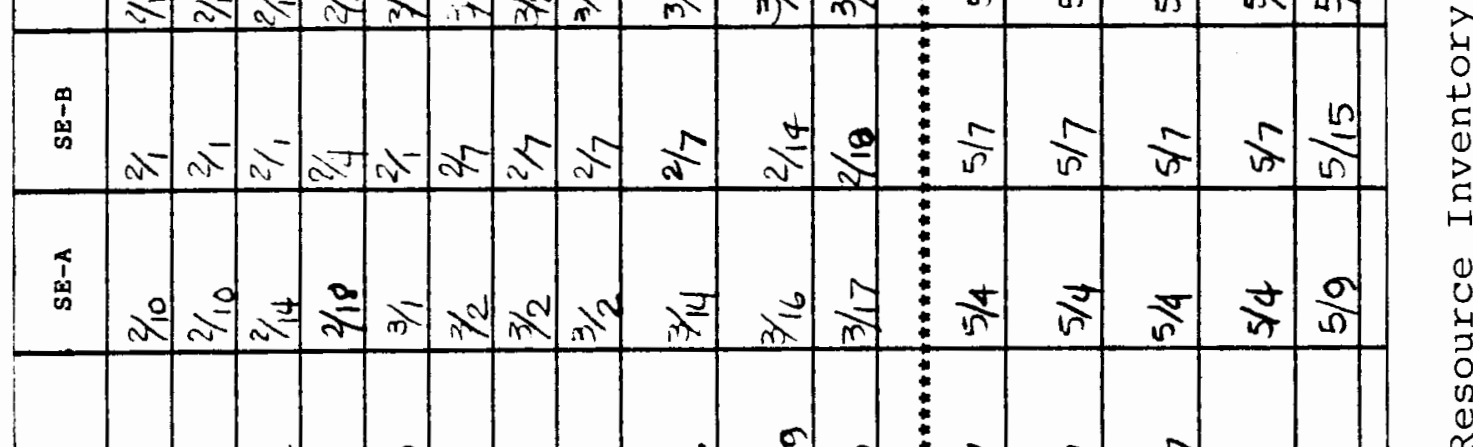

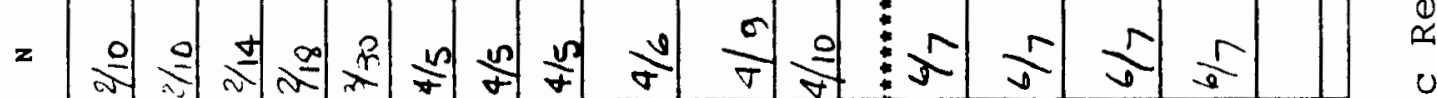

0
.4
0
0
0
0
-1
1

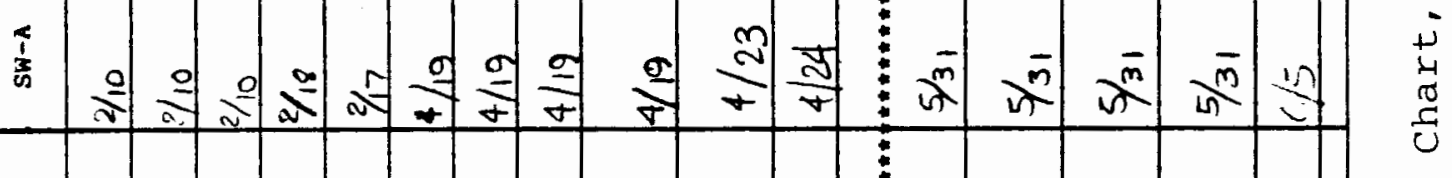

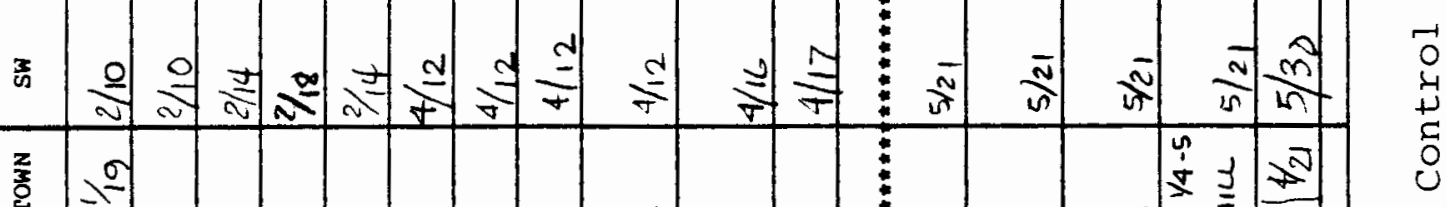

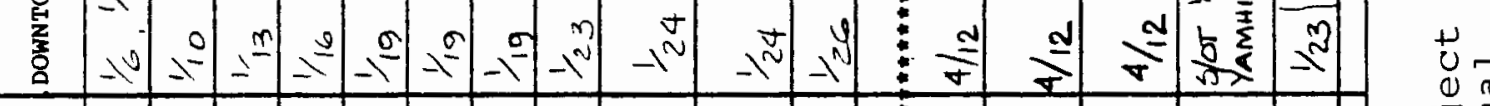

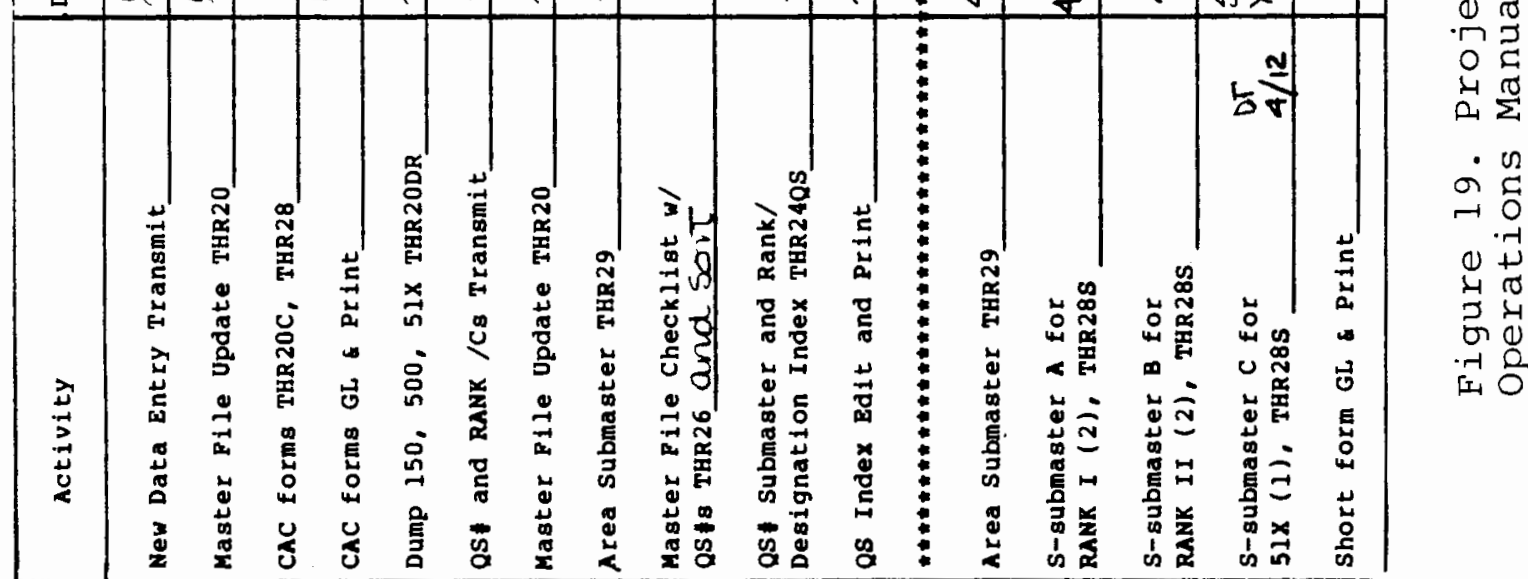


CHAPTER VII

OPERATIONS AND MAINTENANCE

The SCOPE, SYSTEM ORIENTATION, INPUT and OUTPUT sections are designed to describe an automated system and train the user with the ultimate goal of entering information into, and extracting it from, the data base. OPERATIONS AND MAINTENANCE is more miscellaneous in nature. It may contain lots of diverse information, but its overall purpose is to assist the PIC in administering the project.

\section{Risk Management}

The contents of OPERATIONS AND MAINTENANCE depend on the system in use. If the PIC is working with a large computer that requires one or more full-time operators he or she probably will not need to be concerned with the maintenance of the equipment - that will be taken care of by the data processing professionals. If, on the other hand, project data bases are kept on smaller systems that are run by the users themselves, the PIC will need to develop a section that deals with equipment care, insurance, and servicing •

The Risk Management section should begin with a series 
of directives that govern the environment in which the equipment resides. These include climate controls (proper regulation of heat and air conditioning), dust and smoke controls (regular vacuuming, no smoking), and measures for the storage and handing of floppy disks (removal of magnetic fields, storage or filing procedures, and making sure persons know how to handle disks).

The PIC will keep separate files containing insurance policies and service contracts, but notation of their existence is made in the manual, particularly the latter so that persons know who to call and what to do if the system breaks down. Furthermore, all such policies and contracts need to be renewed, and pertinent dates should be recorded to remind present and future PICs to be sure this is done.

\section{Supply Inventory}

This is another section that is more apt to require the PIC's attention if a smaller system is in place, especially if there are multiple users. The supply Inventory is a particularly useful tool over the long term, because it enables the PIC to look back and see what quantities have been used over a given period and budget for future activities. It also serves as a record of where materials are obtained, what they have cost in the past, and how they are ordered. 


\section{Junior League of Portland Supply Inventory}

Item :

Ribbons

Type:

Carbon (for daily use) Diablo Hytype II, cartridge, nylon

Film (for photo-ready copy) Diablo Hytype II, cartriage, multi-strike (M/S)

Order: $\quad$ Systems Supplyware

11612 SW 72nd Ave, Portland 97223

$684-7216$

JLP Acct \#: XXXXXXXX

Price:

$\begin{array}{lrll}\text { Carbon } & \$ 4.65 \text { ea } & (\text { for } 6) \\ M / S & 5.25 \text { ea } & \text { (for 6) }\end{array}$

Last order: $1 / 84$

In stock: Carbon 3

$\mathrm{M} / \mathrm{S} \quad 5$

Figure 20. Sample Supply Inventory, compiled from Junior League of Portland Computer Operations Manual.

Figure 20 is an example of a very simple system that requires the PIC to periodically count the items in stock. Because the inventory is low and the Junior League does not need to track consumption by user, this method works adequately. More detailed inventories may be kept that itemize the number of disks, ribbons, or even sheets of paper used by a given department or person. The PIC may even choose to automate the inventory process itself if large quantities are involved. 


\section{Security}

Password access to a data file may be required for a number of reasons, only one of which is to limit its use for confidentiality purposes. Just as common is the use of passwords as log-ons to identify a user to the machine so that persons can later be billed for computer time.

Security begins with policy statements about authorized use of a data file, who may use it when, whether or not clearance is required, who has priority, and how passwords are obtained. The PIC will then need to maintain a separate, secure file containing a log of all passwords issued.

\section{File Integrity}

This section deals with security as well, specifically the policies and procedures for producing data file backups on a regular basis so that data is never lost. With a small system, this may be as simple as copying the file onto a floppy disk each time it is updated, and keeping that floppy in a secure place.

Large systems, on the other hand, are more regulated. A data processing department generally has set policies for the length of time files are held on an active disk (at the City of Portland it is 7 days) and the PIC must be sure to make a tape back-up of a data base if it is going to sit 
idle for longer than the prescribed length of time. This is much more apt to be the case with a batch processing system where printed reports are the primary output. On-line systems by their very nature are used and updated almost constantly.

A record of tape back-ups may be kept two ways. The first is in the Job Control Register, illustrated in Figure 18. The final job listed there is THRGENDT, a disk-to-tape program that copied the master file, THRl023, onto a tape, giving it the name PHR1020. When the job is run, the computer returns a message to the user telling him that it is successful and displaying the name of the tape on which PHRl020 is stored. This is called the volume serial number, or vol ser, and the user has recorded it next to the job description. The next time he needs to reload the file, he refers to Register, notes the vol ser number (004949), and runs a tape-to-disk program that returns the file to an active disk.

If back-up tapes are used and reused frequently, the PIC may choose to keep a Tape Assignment Log. This record is arranged by tape number instead of by job and tells the PIC when a tape is no longer current. Figure 21 is an illustration of the Assignment Log used for Historic Resource Inventory archive tapes kept at the Portland Archives. The data base was copied first onto RMS00l, then 
RMS002, then RMS003, each time a more updated generation. Since it was HRI policy to keep at least two generations backed up, when the time came for a fourth copy, the first tape was reused. Most practically, the Job Control Register and Tape Assignment Log are used together, one recording assignments by job, the other by tape ID.

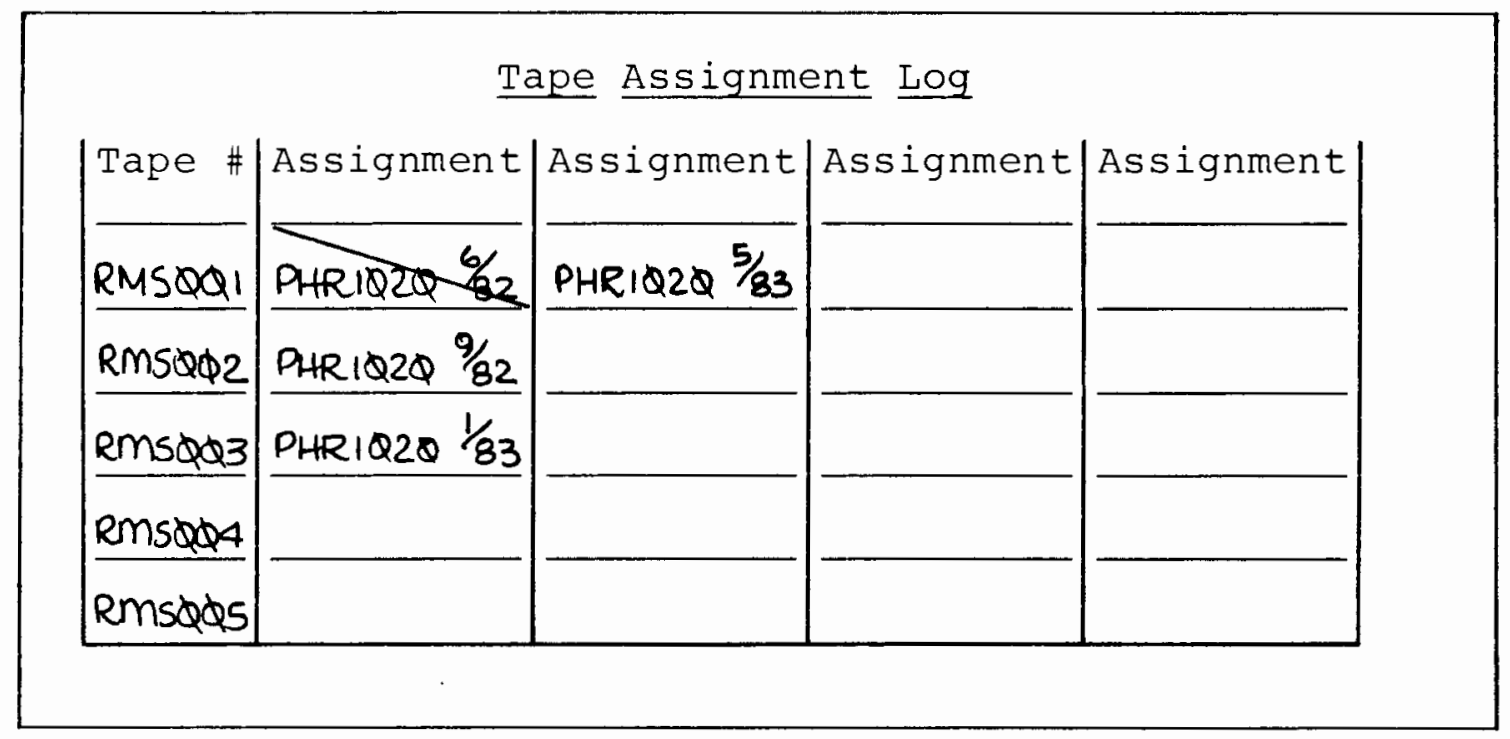

Figure 21. Archive Tape Assignment Log, Historic Resource Inventory SPINDEX Operations Manual.

\section{Work Plan}

The final, often the most important, section of OPERATIONS AND MAINTENANCE is the Work Plan. This document is the PIC's guide to the project and primary administrative tool. In the SCOPE section, the Project Introduction set forth general goals and objectives. These are "to" phrases, which describe the products to be achieved. The Work Plan is composed of "do" phrases which enumerate the activities 
involved in achieving them. These tasks generally fall into groups or phases, like data collection, data entry, editing, updating, routine reporting, and special reports and publications. Once these categories and activities are identified, the PIC builds on them, assigning staff persons to carry them out, determining a schedule and/or deadline for each phase and inserting the dollar amount budgeted.

Much of the Work Plan is actually developed in the project's planning phase, but if there is one characteristic of this document that prevails above all others it is that it is constantly changing as the project proceeds, as some activities are completed, others are revised, and new ones developed. A data base is never static, and the Work Plan will reflect how it is being used. It is also the foundation on which the PIC develops controls for the project to be sure that work is proceeding on schedule and according to budget.

The following example is extracted from the Portland Historic Resource Inventory contract for 1983-84. This was the final phase of a four-year effort to enter properties into the data base and produce a ten-volume publication of profiles (called short forms). Previous cost overruns made it necessary to track expenses very carefully. The overall work plan was composed of ten tasks. Task \#6 is detailed below. 


\section{HRI Work Plan 1983-84}

Task \#6

Produce short forms for final report for RANK I, II, LANDMARK, and NATIONAL REGISTER properties, approximately 750 in all. Inventory Coordinator has provided layout.

Task follows master file update and correction process.

Generate submaster for each area (THR29).

Run each through photocomp program (THR28).

Transmit output to Remote 6 at PARC.

Run through WANG glossary programs, edit.

Print two per page per specifications provided.

Budget: $\$ 2,100$

Data Entry: 48 hours @ $\$ 20$ \$ 960

Recds Mgmt Processing: 12 hours (a) $\$ 30 \quad 360$

Data processing charges 200

WANG Equipment rental: 48 hours a $\$ 10 \quad 480$

$\begin{array}{ll}\text { Supplies } & 100\end{array}$

Figure 22. Extract, Work Plan 1983-84, Historic Resource Inventory SPINDEX Operations Manual.

Referring back to Figure 18, the HRI Project Control Chart, the reader can see the reporting controls developed for this task below the line of asterisks. As each step was completed, the date was recorded in the appropriate space. 
A second control was developed to keep track of costs. An Expense Log was kept for each task, describing it and specifying the budgeted amount and allowable expense codes.

Historic Resources Inventory / Records Management

Services Contract

Expense $\log$ doc $0175 \mathrm{U}$

disk $0004 \mathrm{U}$

Task 16: Short forms for final report, Ranks I, II, Landmark and National Register properties

Contract Amount: $\quad \$ 2,100$

Expense Codes:

Wages: (A) Archivist: $\quad \$ 9.83 / \mathrm{hr}+36 \%+10 \%=\$ 14.70 / \mathrm{hr}$

(WP) WP Operator: $\$ 8.59 / \mathrm{hr}+37 x+10 \%=\$ 12.94 / \mathrm{hr}$

(PT) Part-Tine: $\quad \$ 5.86 / \mathrm{hr}+7 \boldsymbol{T}+100=\$ 6.89 / \mathrm{hr}$

Equipment: (WG) Wang: $\$ 5.00 / \mathrm{hr}$

DPA: (DPA)

Tracking:

I0 Date Hours / Cost

Accrued
Hours $/$ Cost
$\frac{4}{4} / \$ 58.80$
$\frac{5}{6} / \$ \frac{88.20}{102.90}$

Figure 23. Expense Log for Task \#6, Historic Resource Inventory SPINDEX Operations Manual. 
As each hour was spent, it was recorded and a cumulative tally maintained. The PIC could check the Expense Log for any task in progress to be sure it wasn't going over budget.

The work Plan is the control against which the project's progress is measured. Automated systems are made up of equipment, people, time, and money, and to administer them all requires having a way to keep track of resources, spot problems, and accomodate changes. 
CHAPTER VIII

\section{CONCLUSION}

After six years of observing archivists and clients often struggling with implementing automated systems, this writer has come to the conclusion that what they need is not necessarily technical advice (though this is frequently in order), but records management assistance -- guidelines for organizing their own material and meeting certain documentation standards. Although there is a wealth of literature about this subject in regard to software programs (if one has the technical expertise to understand it), there are few guides for in-house applications. This is particularly the case for smaller systems.

A project manual should be whatever the archivist needs it to be. It exists to describe an automated system, train staff, and serve as an ongoing record of activities. It is a fluid, constantly updated, and much used set of documents. SCOPE is a record of the project's purpose and provides general information about the equipment. SYSTEM ORIENTATION is a training tool that describes the hardware and software in more detail. INPUT and OUTPUT are the core of the manual for the user - they describe functions, tell the user how to 
carry them out, and then help him or her keep logs of what has transpired. OPERATIONS AND MAINTENANCE is the section most frequently used by the PIC to maintain the system and administer the project.

The models in this text are just guidelines, examples of what this PIC has used in the past. Each archivist must decide what to use or not, and what new techniques to develop to make running his or her project easier. Designing an automated system is an exciting, creative process in which the archivist, as a manager, must determine how computer, staff, and information can be coordinated to improve operations. Developing project documentation helps to cement this process, and provides the tools to help a system run smoothly and efficiently. 


\section{BIBLIOGRAPHY}

Alldredge, Everett O. "Documenting Computer Operations." Records Management Quarterly (April, 1967): 13 .

Boss, Richard W. and McQueen, Judy. "Automated Circulation Control Systems." Library Technology Reports 18,2 (March/April, 1982 ).

Byrum, John D. and Judith S. Rowe. "An Integrated, UserOriented System for the Documentation and Control of Machine-Readable Data Files." Library Resources and Technical Services $16,3(1972): 338-346$.

Bureau of Traffic Engineering, see Portland, Oregon (City of) Records Management Division, Portland Archives and Records Center.

Cahill, Andy. "Document Production in the Real world." Asterisk 10, 3 (October 1984): 3 .

Cook, Michael. Archives and the Computer. Iondon: Butterworth's and Company (Publishers) Ltd., 1980.

Dewhitt, Ben. "Archival uses of Computers in the United States and Canada." American Archivist 42 (April 1979): $132-157$.

Durr, W. Theodore. "Some Thoughts and Designs About Archives and Automation." American Archivist 47, 3 (Summer, 1984): 271 .

Fagerlund, Liisa. City of Portland Archives Guide. Portland OR: Portland Archives and Records Center, 1982.

Federal Computer Performance Evaluation and Simulation Center. Computer Model Documentation Guide. Washington DC: National Bureau of Standards Special Publication $500-73,1981$.

Fife, Dennis W., Computer Software Management: $\underline{A}$ Primer for Project Management and Quality Control. Washington $\overline{\mathrm{DC}}$ : National Bureau of Standards Special Publication 500$11,1977$. 
Gass, Saul I. Computer Model Documentation: A Review and an Approach. Washington DC: National Bureau of Standards Special Publication 500-39, 1979.

Hannestad, Steven E. "SPINDEX II: A Computerized Approach to Preparing Guides to Archives and Manuscripts." Computing in the Humanities (Serge Lusignan and John S. North, eds.). Waterloo: University of Waterloo Press, 1977 .

Hickerson, H. Thomas. Archives and Manuscripts: An Introduction to Automated Access. Chicago: Society of American Archivists, 1981 .

Historic Resource Inventory, see Portland, Oregon (City of) Records Management Division, Portland Archives and Records Center.

Houghton-Alico, Doann. "Assessing Documentation Needs." Software News (February, 1984): 22 .

Houghton-Alico, Doann. "Developing a Documentation Methodology." Software News (April, 1984): 44.

Junior League of Portland, see Kolve, Carolee et al and Moller, Austin.

Kesner, Richard M. Automation for Archivists and Records Managers: Planning and Implementation Strategies. Chicago: American Library Association, 1984 .

Kesner, Richard M. Information Management, Machine-Readable Records, and Administration: An Annotated Bibliography. Chicago: Socity of American Archivists, 1983.

Kolve, Carolee; Neill, Katy; Freed, Marsha. Junior League of Portland Computer Training Manual. Unpublished typescript, 1984 .

Leong-Hong, Belkis and Marron, Beatrice. Database Administration: Concepts, Tool, Experiences, and Problems. Washington DC: National Bureau of standards Special Publication 500-28, 1978.

Maedke, wilmer 0 . et al. Information and Records Management (2nd edition). Encino, CA: Glencoe Publishing Company, 1981 . 
Martin, Roger J. and Osborne, Wilma M. Guidance on Software Maintenance. Washington DC: National Bureau of

Standards Special publication 500-106, 1983.

McCann, Daniel. "MBO: How it is Structured and Coordinated." MBO: What's in it for you (John M. Roach, ed.). New YOrk: AMACOM, 1975 .

Moller, Austin. Data Entry Instructions and Style Manual, Junior League of Portland Membership Information System. Unpublished records, 1984.

Moller, Austin. Junior League of Portland Computer Operations Manual. Unpublished records, 1984.

Moller, Austin. "Planning for Automated systems in Archives." Paper presented at the Society of American Archivists Annual Conference, Washington DC, 1984 .

Morrisey, George L. "Without Control, MBO is a waste of Time." MBO: What's in it for You (John M. Roach, ed.). New York: AMACOM, 1975 .

Norman, Donald A. "Some Observations on Mental Models." Five Papers on Human-Machine Interaction. Dan Diego: UCSD, 1982. ERIC ED 222195.

Portland, Oregon (City of) Bureau of Planning. Proposed Portland Historic Resource Inventory Project. Portland OR: Bureau of Planning, 1979 .

Portland, Oregon (City of) Records Management Division, Portland Archives and Records Center. Historic Resource Inventory Working Papers. Unpublished records, 19791984 .

Portland, Oregon (City of) Records Management Division, Portland Archives and Records Center. Historic Resource Inventory SPINDEX Data Entry Instructions and Style Manual. Unpublished records, 1981.

Portland, Oregon (City of) Records Management Division, Portland Archives and Records Center. Historic Resource Inventory SPINDEX Operations Manual. Unpublished records, 1982 . 
Portland, Oregon (City of) Records Management Division, Portland Archives and Records Center. Bureau of Traffic Engineering Library Reference Guide and Updating Procedures Manual. Unpublished records, 1983.

Sahli, Nancy. SPINDEX: An Introduction for New and Prospective Users. Ellensburg WA: SPINDEX User's Network, 1980 .

Shneiderman, Ben. Software Psychology: Human Factors in Computer and Information Systems. Cambridge MA: Winthrop Publishers, Inc., 1980.

Simpson, Henry. "A Human-Factors Style Guide for Program Design." BYTE 7, 4 (1982): 108-132.

Smithsonian Institution. Smithsonian Institution Bibliographic Information System (SIBIS) Implementation of USMARC Format for Archives and Manuscript Control. Unpublished typescript, 1984 .

Smithsonian Institution. Proposed Format for SIBIS Circulation Module. Unpublished typescript, 1984.

United States Department of Commerce, National Bureau of Standards. Guidelines for Documentation of Computer Programs and Automated Data Systems. Washington DC: National Technical Information Service FIPS Publication \#38, 1976 .

United States General Services Administration. SPINDEX II: Report and Systems Documentation. Washington DC: National Archives and Records Service, 1975.

United States General Services Administration. SPINDEX III: Report and Systems Documentation (unpublished). Washington DC: National Archives and Records Service, 1983.

Vorhaus, Louise. "Taking the Pain Out of Documentation." Office Administration and Automation (March 1984): 57 . 